\title{
THE RATIONAL USE OF FINITE ELEMENT METHOD IN THE ANALYSIS OF FLEXIBLE PAVEMENTS
}

\author{
Abd Alla E. M. \\ Civil Engineering Department, Faculty of Engineering, Assiut University, \\ Assiut, Egypt.
}

(Received May 27, 2006 Accepted June 29, 2006)

\begin{abstract}
The environment, traffic loading, material properties and construction practices are main factors influencing pavement performance. Traffic loading with different wheel configurations is simultaneously moving on highways. Moreover, the pavement boundary conditions affect pavement behaviour. To predict pavement responses and performance, traffic loads with different characteristics are considered to estimate stresses and deformations through pavement. These responses in case of layered pavement system are less than those obtained for the ideal homogeneous case depending upon the stiffness of the layers. Semi-analytical solutions are available to analyze the behaviour of elastic layered pavement subjected to traffic loads. For more complex cases of layered pavement or loading conditions, it is necessary to perform numerical analysis using finite element technique. In addition, most of pavement materials do not linearly perform under the action of traffic loading. Therefore, linear and non linear analyses were preformed for first series of the investigation, which take in account the effect of tyre pressure, axle load, asphalt layers rigidity and pavement layers properties. Also, the influence of state of loading, tyre type and some boundary conditions on pavement responses is considered in the second series. Furthermore, for moving traffic loads, the effects of viscous damping, and load frequency on the deflection and stress have been investigated. In this paper, the ANSYS programs version-8 and version-10 are used to analyze in three dimensions the behaviour of layered pavement systems under static and moving vertical loads and to obtain stresses and deflections through it considering the realistic properties of the pavement layers indicating load transmission issues for a wide variety of materials stiffness. In this research, the pavement is modeled as a multilayered elastic system composed of a subgrade assumed to be an infinite medium upon which layers of finite thickness infinitely extended horizontally are laid. Discussing and analyzing of obtained results are presented and the main conclusions are drawn out.
\end{abstract}

\section{INTRODUCTION}

The pavement performance is influenced by factors such as material properties, the environment, traffic loading, and construction practices. Also, pavement damage may be caused by vehicle characteristics, axle load and wheel configuration. Pavement responses are affected by both load and tyre pressure. But, the load has a greater effect 
than tyre pressure. The effect of increased tyre pressure is significant in the asphalt surface layer in terms of vertical compressive stresses, and the magnitude of the maximum tensile strain at the bottom of asphalt base layer increases with the increased tyre pressures. Further more, tyre type, axle load, and axle configuration have significant effects on those responses. When the induced strains due to external loads are relatively small, stresses and deformations are usually estimated using the theory of elasticity. Semi-analytical and analytical solutions are available to analyze the behaviour of elastic layered pavement subjected to surface loads. In solutions concerning the analysis of layered pavement systems under traffic load, the pavement layers are considered as homogeneous, linear elastic, isotropic and the loading is considered as static. These methods such as Boussinesq's one work reasonably well if the pavement system behaves as a linear elastic system. The stress and deformation distributions are symmetrical with respect to the vertical axis of acting load at any depth below the surface. When the soil mass consists of layered strata of finer and coarser materials or non-isotropic soils, the Boussinesq equations may not provide reliable solution. Modified form of Boussinesq's equation considers equivalent height of pavement layers, which assumed that the pavement layers are acting as a single homogeneous incompressible layer and stiffness factor of layers was derived. Then the vertical stress in subgrade can be obtained. In the solution according to two-layer system, the total surface and interface deflections can be obtained. Burmister provided analytical expressions for stresses in three layer elastic systems, which had been expanded by Jones and Peattie. In recent years, means of numerical techniques such as the finite element method for pavement analysis is used. In 2-dimensional finite element analysis of multi-layered pavement, two relations and two charts were developed. The first is used to obtain the relative stress at subgrade with respect to applied one at pavement surface with respect to the total equivalent height of pavement and the second is used to compute pavement surface deflection beneath the center line of applied load with respect to the similar height [1-13].

In the real situation, heterogeneous pavement layers behave far from such ideal conditions. Pavement materials are not behaving in a linear elastic manner and the materials behave non-linearly. For relatively thick asphalt construction, linear elastic theory for a wheel load may be valid, where for thin asphalt construction the non-linear characteristics of the granular layers and soil dominate the response to wheel load, nonlinear analysis is required. Therefore, the proper selection of material properties is very important to improve the prediction of those behaviours [7].

Wheel load stresses and deflections have often been calculated using static load conditions, however, moving dynamic loads induces critical wheel load stresses and deflections. The primary response parameters of the pavement depend on vehicle speed. The moving load produces a higher deflection at the top of the subgrade than the static loading with non-linear pavement materials. In addition, dynamic effects are less pronounced for the stiffer pavement structures. No simple relations between static and dynamic displacements exist, but a general trend of decreasing dynamic/static surface deflection with increasing frequencies is apparent. Stress pulses develop within the pavement layers due to a truck wheel moving on the road. The pulse duration increases with decreasing the vehicle speed and the magnitude of the pulse gets smaller when the depth increases since the load is distributed over larger areas. The pulse shape varies 
largely when the speed changes. Moreover, the shape of the stress pulse becomes asymmetric when the depth increases, especially at high speeds. The change in deflection with speed is not largely affected by the axle spacing, or pavement stiffness. With a harmonic variation on the moving axle loads, the maximum deflection and stress increase with increasing load frequency considered without viscous damping. But, with viscous damping, the maximum deflection and stress tend to decrease with increasing load frequency. The granular layers and soil dominate exhibit hysteretic behaviour to moving wheel load and material damping ratio of $5 \%$ were specified for all layers including the surface layer [14-20]. The finite element method provided a better solution in analysis of pavement of complex geometry, boundary conditions and materials with considering traffic loading as a static loading, while for the heterogeneity, non-linearity and orthotropy condition of the pavement structure incorporating of traffic loading as a dynamic loading is still in its early stages of research.

This paper illustrates the usefulness of the finite-element method in the analysis of multilayer pavement systems subjected to different types of loading simulating axle loads with different wheel configurations as a statically effect or traveling at different speeds. In this research, the ANSYS programs version-8 and version-10 [21] are used to analyze the flexible pavement as a finite element model, with defined boundary conditions and to investigate the effect of loading when combined with linear and nonlinear characteristics of pavement materials of the layers. Also, the effect of different cases and state of traffic loading, effect of some boundary conditions on the stresses and deformations through the pavement are investigated.

\section{THREE-DIMENSIONAL FINITE ELEMENT ANALYSIS OF MULTI-LAYERED FLEXIBLE PAVEMENT}

For 3-dimensional analysis of pavement structure of non homogeneous materials, it can be efficiently used for the analysis, are ANSYS Programs Version-8 and version-10 [21]. This software is used in this research study for elastic linear and non-linear behaviour of pavement materials under various loading conditions. The tyre type with different wheel configurations is selected for pavement analysis as given in Figs. $\mathbf{1}$ and 2. For first series of analysis of pavement structure, the effect of dual wheel with different tyre pressure, static axle load, and asphalt layers stiffness are conducted. For second series of analysis of pavement structure, the effect of tyre type, pavement boundary condition and state of traffic loading are investigating.

\subsection{Pavement System Under The Effect Of Static Wheels.}

\subsubsection{Case of elastic-linear characteristics of pavement materials}

For analysis of pavement structure, the layers thicknesses in the pavement model have been chosen such that they are close to those of the existing pavement. The pavement structure selected for this study consists of $50 \mathrm{~mm}$ of dense graded asphalt concrete surface course and $50 \mathrm{~mm}$ thick binder course, a $150 \mathrm{~mm}$ thick granular crushed limestone layer as the base course, a $250 \mathrm{~mm}$ thick of gravel-sand soil as the subbase course and a subgrade (silty soil) at the bottom. The configuration for the structure used in the analysis is illustrated in Fig. 3. The material characteristics used in the 
analyses, considered to be representative of the various layers in the selected pavement structures, are summarized in Table 1.

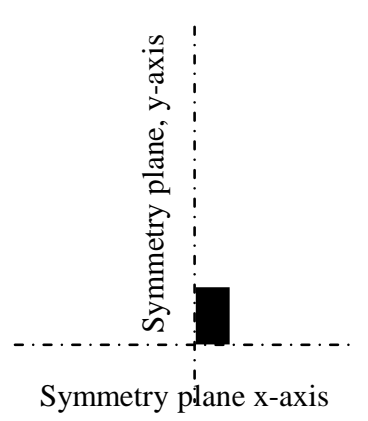

(a) Single-axle single-tyre

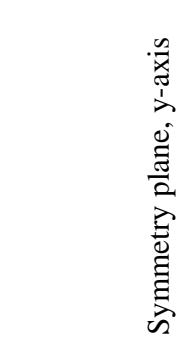

Symmetry plane $\mathrm{x}$-axis

(b) Single-axle dual-tyre

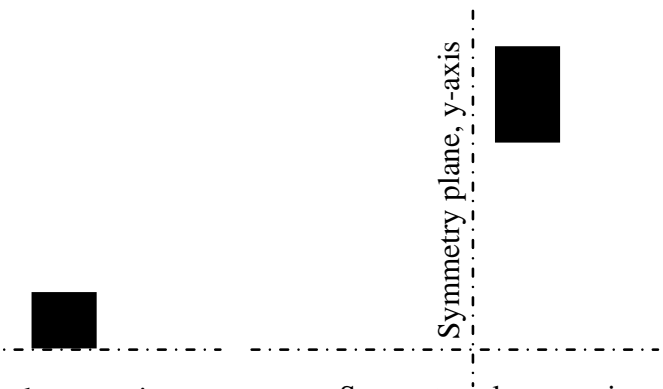

Symmetry plane $\mathrm{x}$-axis

(C) Single-axle dualtandem tyre

Fig. 1 Wheel configuration considered in analysis as a static load.

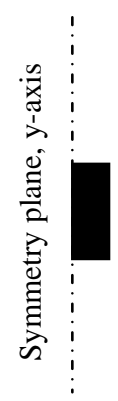

(a) Single-axle single-tyre

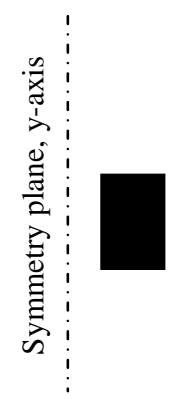

(b) Single-axle dual-tyre

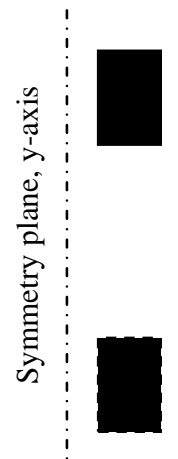

(c) Single-axle dual-tandem tyre

Fig. 2: Wheel configuration considered in analysis as a moving load.

To analyze the pavement system shown in Fig. 3, the pavement is modeled as a finite element model, using ANSYS Program Version-8. The pavement configuration selected for calculation is shown in Fig. 4. The pavement block is modeled with SOLID45 brick elements quadratic with 8-node. The element has three degrees of freedom at each node: translations in the nodal $\mathrm{x}, \mathrm{y}$, and $\mathrm{z}$ directions and rotation are not allowed for all nodes [21]. The finite element model representing the pavement considered in this analysis, and mesh generation are shown in Fig. 5.

The boundary conditions are defined at the nodes where the displacements in horizontal and vertical directions can be restrained. The following conditions are applied with reference to Fig. 4, when defining the boundary conditions.

- The vertical displacements of the nodes on the bottom plane (plane ABCD) of the model are fixed.

- The plane ADGF is considered as plane of symmetry between the two wheels, thus the orthogonal displacements to the plane are prevented. 
- The plane ABEF is considered as vertical plane passing through midway of one wheel, thus the orthogonal displacements to the plane are prevented

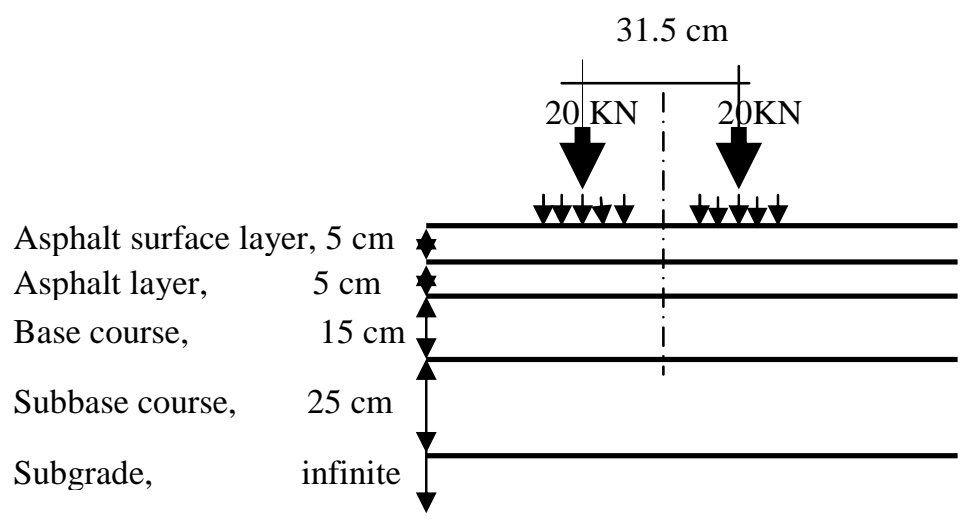

Figure 3 Pavement configuration

Table 1: layer thickness and elastic material properties used for analysis.

\begin{tabular}{|l|l|l|l|l|l|}
\hline Layer & Material & $\begin{array}{l}\text { Thickness, } \\
\mathrm{cm}\end{array}$ & $\begin{array}{l}\text { Unit Weight, } \\
\mathrm{kg} / \mathrm{m}^{3}\end{array}$ & $\begin{array}{l}\text { Young's } \\
\text { Modulus, } \mathrm{kg} / \mathrm{cm}^{2}\end{array}$ & $\begin{array}{l}\text { Poisson's } \\
\text { Ratio }\end{array}$ \\
\hline 1 & Surface layer & 5 & 2400 & $10000-30000$ & 0.4 \\
\hline 2 & Binder course & 6 & 2350 & $5000-15000$ & 0.4 \\
\hline 3 & Base & 15 & 2200 & 1500 & 0.3 \\
\hline 4 & Sub-base & 25 & 2000 & 1000 & 0.3 \\
\hline 5 & Subgrade & infinite & 1500 & 200 & 0.45 \\
\hline
\end{tabular}

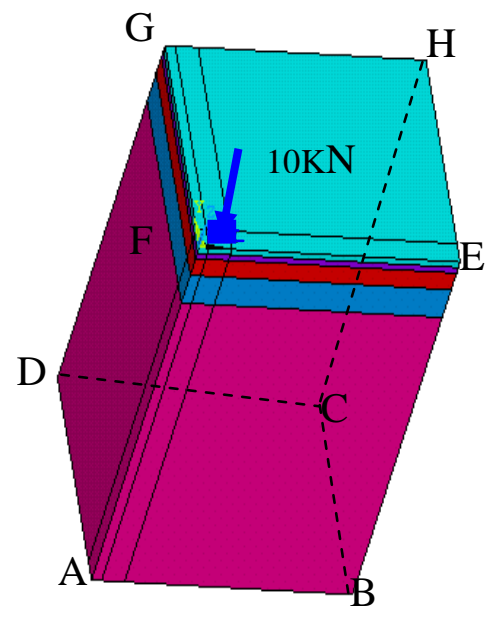

Fig. 4: Pavement configuration used in the analysis

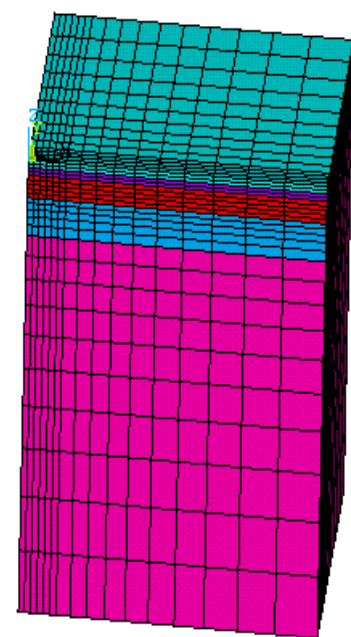

Fig. 5: Three-dimensional view of the finite element model. 
This configuration gives more realistic representation of the pavement, and the load is also repeated on either side of the symmetry boundary. The analysis is run in a plane strain configuration. In this type of analysis, the loading is applied as traffic static loading of axle equal to $80 \mathrm{KN}$ applied through a dual wheel assembly spaced by $31.5 \mathrm{~cm}$. The $20 \mathrm{KN}$ wheel load is assumed to be uniformly distributed over the contact area between each tyre and pavement. A contact pressure equals to $570 \mathrm{KN} / \mathrm{m}^{2}$ (tyre pressure of commercial vehicle) is assumed, i.e. $5.77 \mathrm{~kg} / \mathrm{cm}^{2}$. The contact area can be represented by two semicircles and rectangle as shown in Fig. 6. This previous shape is converted to a rectangle as suggested by Ref. [7], having an area of $0.5228 \mathrm{~L}^{2}$, then the contact area has the dimensions of $22.6 \times 15.6 \mathrm{~cm}$.

Due to symmetry, the pavement under a half wheel load is considered in the analysis. A pavement block under half wheel load, having a length of $183.6 \mathrm{~cm}$, width of $131.35 \mathrm{~cm}$, and a depth of $300 \mathrm{~cm}$, is considered for the analysis as shown in Fig. 4 . The effect of increasing contact pressure is conducted. Therefore, another contact pressure of $8.44 \mathrm{~kg} / \mathrm{cm}^{2}$ on the same selected contact area is used for analysis. Furthermore, the effect of increasing axle load was studied. Thus other runs were performed for a model representing the pavement under the effect of an axle loads of 9.3-13.6 ton for contact pressure of both 5.77 and $8.44 \mathrm{~kg} / \mathrm{cm}^{2}$ and pavement block under half wheel load, having a length of $191.1 \mathrm{~cm}$ and width of $152.9 \mathrm{~cm}$, and a depth of $300 \mathrm{~cm}$, are considered.

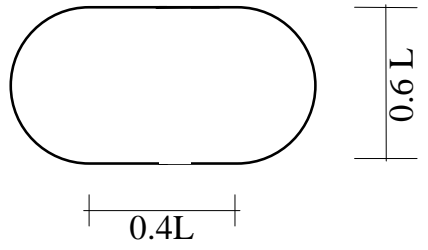

Fig. 6a: contact area between tyre and pavement surface.

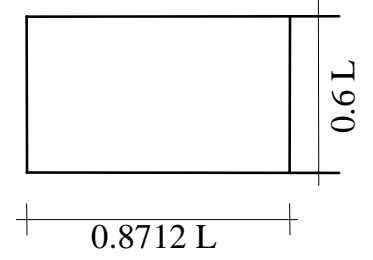

Fig. 6b: Equivalent contact area.

\subsubsection{Case Of Elastic-Non Linear Characteristics Of Pavement Materials}

The behaviour of unbound pavement materials with thin asphalt layer is certainly nonlinear and stress dependent, even at low traffic stresses. For pavement analysis, a nonlinear finite-element model with stress dependency is suitable for calculating a reduced horizontal tension in the bottom half of unbound aggregate base layers. It is also noted that the effects of nonlinearity and the varying stress-dependent modulus and Poisson's ratio, especially in the base layers, could be substantial [12].

Therefore, the finite element computer program ANSYS Program Version-8 was used for pavement analysis considering the non linearity of the pavement materials. The Durcker-Brager yield criterion is used in this study as a simple pressure dependent failure criterion. It can be viewed as a smooth approximation to the Mohr- Coulomb criterion. Since the values of c (cohesion) and $\varphi$ are determined by using conventional triaxial compression tests, they are different from those determined under plane strain conditions. The value of Drucker Brager constant can be expressed as [22]: 


$$
\tan \alpha=\frac{\tan \varphi}{\sqrt{\left(9+12 \tan ^{2} \varphi\right)}}
$$

where $\alpha=$ angle of flow (the inclination of yield surface),

$\varphi=$ angle of internal friction

The values of cohesion, angle of internal friction and angle of flow in addition to the initial values of Young's modulus and Poisson's ratios for different materials used in the analysis for non linear behaviour of pavement layers are assumed and shown in Table 2 [7, 14 and 22]. The pavement structure, configuration and loading conditions selected for calculation; finite element mesh and the boundary conditions are similar as in the case of linear analysis (Figs. 3-5). The 3-dimensional analysis is run in a plane strain configuration. The pavement block is modeled with SOLID45 brick elements.

Table 2: layer thickness and elastic material properties used for non linear analysis.

\begin{tabular}{|c|l|c|c|c|c|c|}
\hline Layer & \multicolumn{1}{|c|}{ Material } & $\begin{array}{c}\text { Initial Young's } \\
\text { Modulus, kg/cm }\end{array}$ & $\begin{array}{c}\text { Poisson's } \\
\text { Ratio }\end{array}$ & $\begin{array}{c}\mathrm{C}, \\
\mathrm{kg} / \mathrm{cm}^{2}\end{array}$ & $\begin{array}{c}\text { Friction } \\
\text { angle, } \varphi\end{array}$ & $\begin{array}{c}\text { Angle of } \\
\text { flow, } \alpha\end{array}$ \\
\hline 1 & Surface layer & $10000-50000$ & $0.35-0.4$ & $2.5-40$ & $30-35$ & 10 \\
\hline 2 & Binder course & $5000-15000$ & 0.4 & 2 & 35 & 10 \\
\hline 3 & Base & $850-1500$ & 0.3 & $0.01-0.4$ & 55 & 14 \\
\hline 4 & Sub-base & $500-1000$ & 0.3 & $0.03-0.3$ & 45 & 12 \\
\hline 5 & Subgrade & $100-200$ & 0.4 & $0.1-1.0$ & 20 & 2 \\
\hline
\end{tabular}

\section{The vertical stress $\sigma_{z}$ load step increments curve}

To check the accuracy of the used program, Figure 7 shows the relationship between the stress $\sigma_{z}$ and the increments (load steps) of equivalent single wheel load at specified point (at surface) through the center line of dual wheel load assembly obtained from linear and nonlinear solutions using the ANSYS program. The nonlinearity solution performed using Drucker Brager criterion is compared by linear solution. The linear solution assumed that there is no yield surface and then the behaviour of materials is

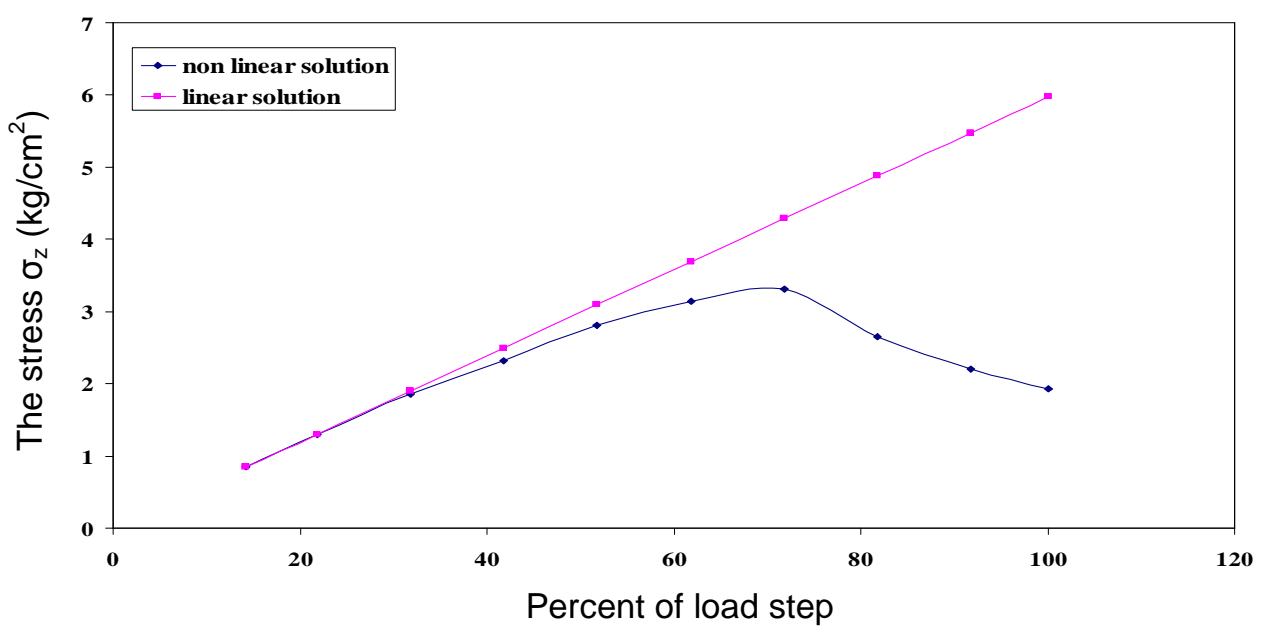

Fig. 7: The linear and non-linear solutions of selected flexible pavement. 
always elastic. But in non linear solution, the yield surface is assumed as Drucker Brager criterion. Therefore, if the stress acting on the material is inside the yield surface, the partial solution is linear followed by nonlinear solution due to the hardening of material where the yield surface expanded isotropically until it fails.

\subsubsection{The Effect Of Tyre Type On The Behaviour Of The Pavement}

For study the effect of tyre type (wheel configurations) on the behaviour of the pavement system, another pavement structure, which consists of $10 \mathrm{~mm}$ of dense graded asphalt concrete surface course $\left(\mathrm{E}=50000 \mathrm{~kg} / \mathrm{cm}^{2}, \mu=0.35, \varphi=30, \mathrm{c}=\right.$ $\left.40 \mathrm{~kg} / \mathrm{cm}^{2}\right)$, a $200 \mathrm{~mm}$ thick granular crushed limestone layer as the base course $(\mathrm{E}=$ $\left.850 \mathrm{~kg} / \mathrm{cm}^{2}, \mu=0.3, \varphi=55, \mathrm{c}=0.4 \mathrm{~kg} / \mathrm{cm}^{2}\right)$, a $200 \mathrm{~mm}$ thick of gravel-sand soil as the subbase course $\left(E=500 \mathrm{~kg} / \mathrm{cm}^{2}, \mu=0.3, \varphi=45, \mathrm{c}=0.3 \mathrm{~kg} / \mathrm{cm}^{2}\right)$ and a subgrade at the bottom $\left(\mathrm{E}=100, \mu=0.35, \varphi=20, \mathrm{c}=0.1 \mathrm{~kg} / \mathrm{cm}^{2}\right)$ was selected as shown in Fig. 8 . Tyre types considered in analysis are shown in Fig. 1. In this study, three tyre types were used; an axle single-tyre, dual-tyre spaced by $31.5 \mathrm{~cm}$ and dual-tandem tyre group spaced by $31.5 \mathrm{~cm}$ by $122 \mathrm{~cm}$. The pavement is assumed subject to a static traffic loading of an axle equal to $80 \mathrm{KN}$ with a uniform pressure of $570 \mathrm{kpa}$ within each tyre. Three dimensions finite-element model, using ANSYS Program Version-10, is utilized to simulating loads and pavement structure. The load was applied in 100 increments. The pavement block is modeled with SOLID 45 brick elements quadratic with 8-node [21].

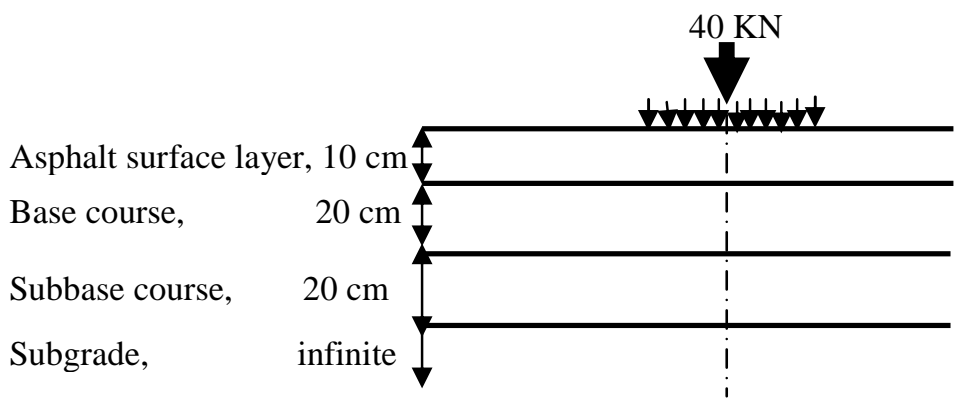

Figure 8 Pavement structure for analysis.

The simulation and analyses were conducted for different tyre types given in Fig. 1. Because of symmetry, only $1 / 4$ of the contact area is analyzed. In the first type of analysis, single axle single-tyre, the pavement configuration selected for calculation is shown in Fig. 9. The finite element model representing the pavement and mesh generation is shown in Fig. 10. In this type of analysis, the tyre-pavement contact area caused by an assumed $40 \mathrm{KN}$ wheel load (single-tyre) is considered and its shape is assumed as rectangular area with the dimensions of $22 \mathrm{~cm}$ by $32 \mathrm{~cm}$. A pavement block under wheel load, having a length of $311 \mathrm{~cm}$, width of $316 \mathrm{~cm}$, and a depth of $350 \mathrm{~cm}$, is considered for the analysis. The boundary conditions are defined at the nodes where the displacements in horizontal and vertical directions can be restrained. The following conditions are applied with reference to Fig. 9, when defining the boundary conditions: 
- The vertical displacements of the nodes on the bottom plane (plane $\mathrm{ABCD}$ ) of the model are fixed.

- The plane ABEF is considered as plane of symmetry through midway of wheel, thus the orthogonal displacements to the plane are prevented.

- The plane ADGF is considered as vertical plane passing through midway of wheel, thus the orthogonal displacements to the plane are prevented .

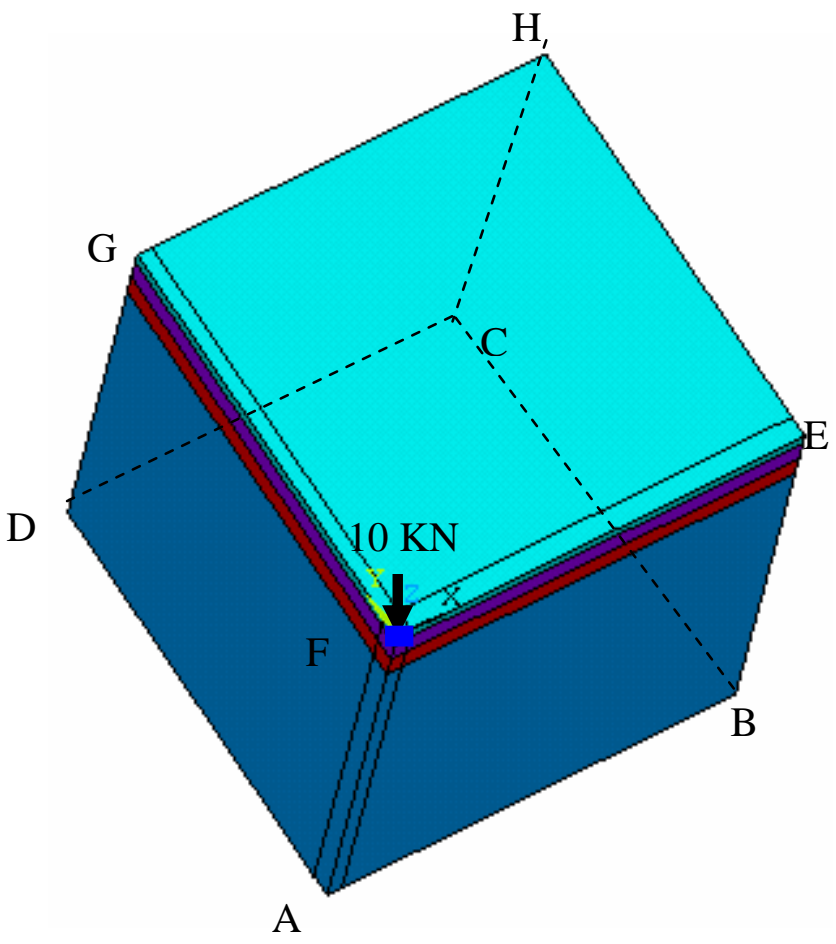

Fig. 9 Pavement configuration used in the analysis (single-tyre).

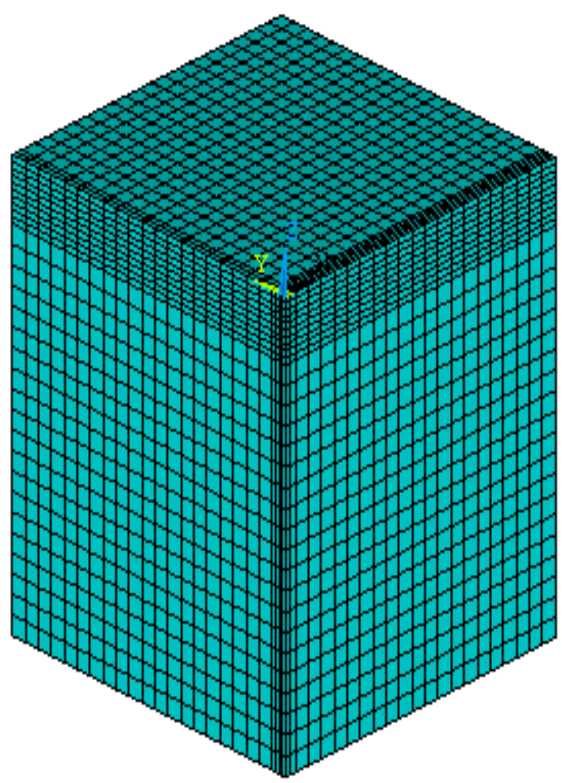

Fig. 10 Three-dimensional view of the finite element model (single-tyre).

\section{Group Simulation}

Two analyses were conducted to investigate the effects of group configuration shown in Fig. 2 on the behaviour of pavement system. The first analysis involved a singleaxle dual-tyre configuration, shown in Fig $\mathbf{2 b}$, with a $40-\mathrm{KN}$ load ( $20 \mathrm{KN}$ per tyre), while the second analysis involved a dual tandem configuration, shown in Fig 2c, with a $40-\mathrm{KN}$ load (10 KN per tyre). In both cases, only $1 / 4$ of the geometry was analyzed.

\subsubsection{Effect Of Boundary Conditions On Pavement Responses}

The shoulder or retaining wall is constructed to increase the stability of pavement. The shoulder sometimes is failed due to environment effect, sliding and materials shrinkage. To investigate the effect of boundary conditions on pavement responses, pavement under the effect of static loads is modeled as a three dimensions finiteelement model, using ANSYS Program version-10. Three cases reflecting the selected 
boundaries are assumed. The first case considered the tight adhesion between the pavement and shoulder, while the second case assumed the crack along the vertical plane between the pavement and shoulder. The third analysis is performed to consider shrinkage crack or failed shoulder to the top level of subgrade. In these analyses, the pavement is subjected to a traffic loading of the same considered axle wheel load (single-tyre) with uniform pressure as given in case of static state. Because of symmetry, only $1 / 4$ of the contact area is analyzed. Therefore, a pavement block under wheel load as given in Fig. 9 is considered for the analysis. The following boundary conditions are applied.

- The vertical displacements of the nodes on the bottom plane (plane ABCD) of the model are fixed.

- The plane ABEF is considered as plane of symmetry through midway of wheel, thus the orthogonal displacements to the plane are prevented.

- The plane ADGF is considered as vertical plane passing through midway of wheel, thus the orthogonal displacements to the plane are prevented.

- The horizontal displacements of the nodes on the vertical plane (plane BCHE) of the model are partly and/or completely fixed to reflect the above mentioned handled cases.

\subsection{Pavement System Under The Effect Of Moving Wheels.}

The analyses were conducted by simulating "moving" loads at different speeds (two different vehicle speeds were used $2.5 \mathrm{~km} / \mathrm{hr}$ and $60 \mathrm{~km} / \mathrm{hr}$ ); and characterizing the viscous behaviour of pavement materials. Different wheel configurations as moving loads are considered in the analyses shown in Fig. 2. In this study also, an axle singletyre is used to reflect the effect of moving wheel load on the behaviour of the pavement system comparison with the similar static wheel. The top surface is considered as free from any discontinuities and the interfaces between layers are considered as fully bonded and rough. A finite-element model is used to analyze flexible pavement subjected to a moving wheel as vertical loads.

\section{Single-Axle Single-Tyre Simulation}

The finite-element discretization of a multi-layer pavement system selected for calculation due to moving wheel loads is shown in Fig. 11. This configuration gives more realistic representation of the pavement, and the load is also repeated on either side of the symmetry boundary. The pavement block is modeled with SOLID 45 brick elements quadratic with 8-node and element Solsh 190 is used to simulate the moving wheel with properties as rubber material. In this type of analysis, the pavement is subjected to a moving vertical traffic loading (single axle single-tyre) as shown in Fig. 2. The rectangular contact area is assumed, having an area of 22 by $32 \mathrm{~cm}$ and any change in the shape during load variation is neglected. Because of symmetry, only $1 / 2$ of the contact area is analyzed, as indicated in Fig. 11. In the analysis, a single-tyre load was assumed to travel along a straight path (Y-axis) at constant prescribed speed, ignoring the effects of the dynamic behaviour of the vehicle. The amplitude variation of the moving loads considered in this study includes harmonic variation. Several analyses were conducted to investigate the effects of damping, frequency and vehicle 
speed due to tyre pressure on the behaviour of the pavement system, assuming the material properties indicated in previous item 2.3 . The following boundary conditions are applied.

- The vertical displacements of the nodes on the bottom plane (plane ABCD) of the model are fixed.

- The plane ABEF is considered as vertical plane passing through midway of wheel, thus the orthogonal displacements to the plane are prevented.

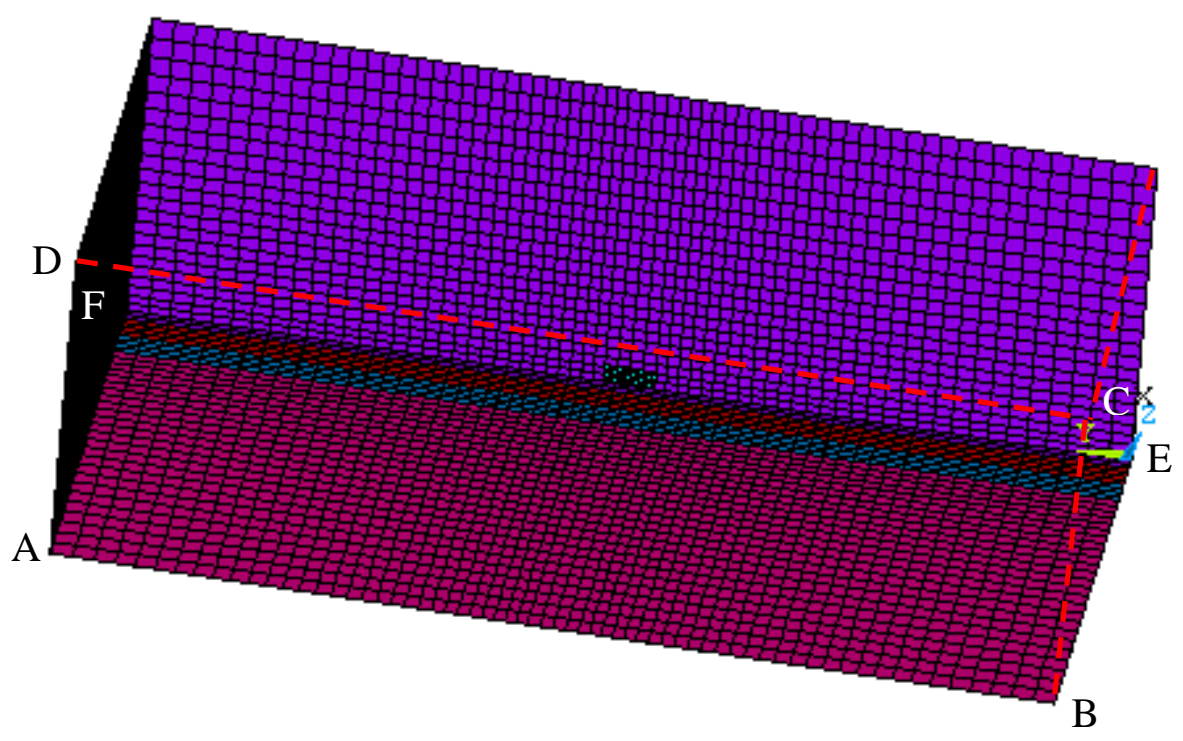

Fig. 11 Three-dimensional view of the finite element model (single-tyre).

\section{PAVEMENT ANALYSIS RESULTS AND DISCUSSION}

The results of all of the analyses obtained in the modeled pavement structures are presented. These results are given in the sequence in which they were accomplished to illustrate the process used to arrive at a proper knowledge of predicted performance of pavement structure. The effect of pavement depth on deflection and stress was determined. The responses obtained at planes of symmetry and through C.L. of wheel at surface and layers interface and subgrade are analyzed and described in the following sections. Figure 12 shows the locations at which deflections and stresses were determined, analyzed and described in the following sections.

\section{Locations}

On surface

On base surface

At subgrade

$\longrightarrow \frac{\text { Asphalt Concrete }}{\text { Base }}$

Figure 12 Pavement surface locations at which deflection and stress were determined. 


\subsection{Case Of Elastic-Linear Characteristics Of Pavement Materials}

The effect of pavement depth on deflections and stresses due to tyre pressure $\left(8.44 \mathrm{~kg} / \mathrm{cm}^{2}\right)$ were presented in Figs. 13, 14. From these figures, it is noticed that the deflection and stress decrease as pavement depth increases. The deflection and stress at plane of symmetry (x-axis) decreases as the distance of plane of symmetry increases depending on pavement depth and on wheel assembly configuration for shallow ones. The stress at shallow depths through C.L. of wheel is greater than that at plane of symmetry "y-axis" (C.L. of wheel assembly configuration).

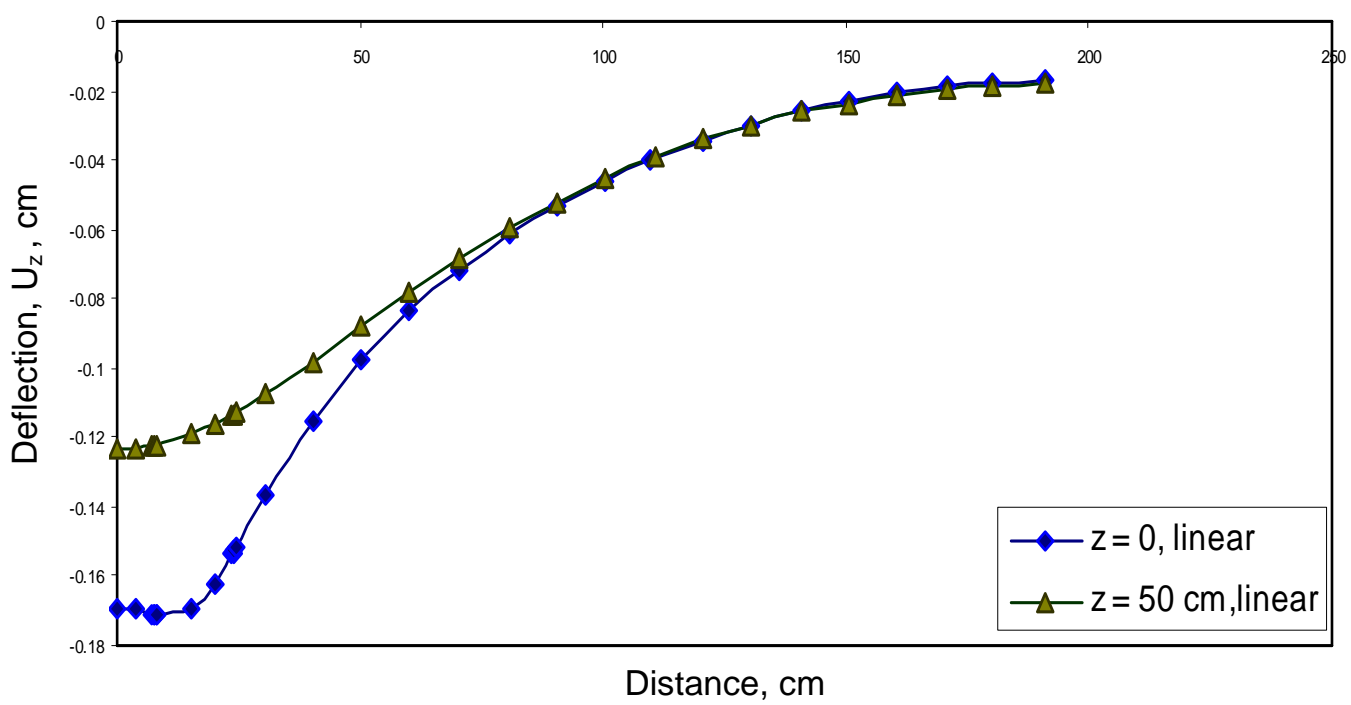

Fig. 13: Deflection of pavement surface and at depth of $50 \mathrm{~cm}$ through $x$-axis .

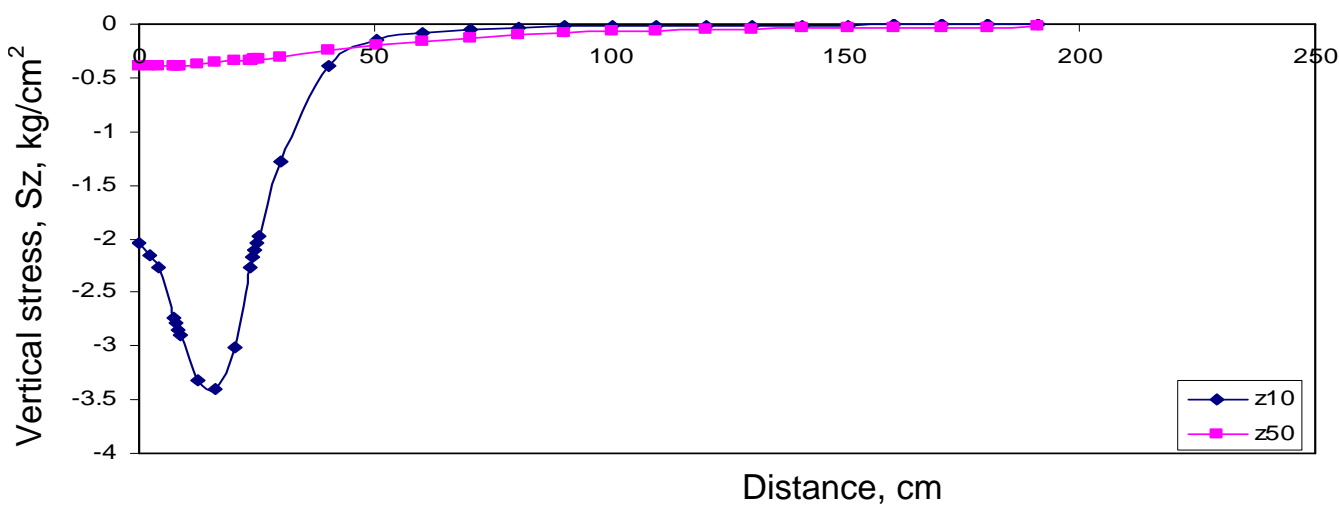

Fig. 14: Vertical stresses at depths of 10 and $50 \mathrm{~cm}$ through $x$-axis.

The maximum vertical stress at depth $50 \mathrm{~cm}$ using firstly, Boussinesq's equation and modified one according to Ref. [10], secondly 2-D analysis Ref. [8], reached $-0.30 \mathrm{~kg} / \mathrm{cm}^{2}$, while it is equal to $-0.39 \mathrm{~kg} / \mathrm{cm}^{2}$ according to the present analysis, i.e. exceeds by $30 \%$ of that obtained according to comparison cases. Also, the maximum 
surface deflection obtained using 2-D analysis and derivative relation given in Ref. [8] equals $0.188 \mathrm{~cm}$, while it reached $0.17 \mathrm{~cm}$ according to the present analysis i.e. less by $10 \%$ of that according to the 2-D analysis. These deviations may be attributed to dimensional effects of considered model and contact area.

\subsection{Case Of Elastic-Non Linear Characteristics Of Pavement Materials}

The deflection due to tyre pressure decreases as pavement depth increases for non linear performance of pavement materials as presented in Fig. 15. Also, these deflections under loading zone at shallow depths decrease depending on resulting equivalent wheel at pavement depth. The value of deflection and stress considering non linearity are larger than those obtained from linear analysis as given in Figs. 15, 16. Considering non linear analysis, vertical stresses through C.L. of tyre are larger than those through C.L. of dual wheel assembly "y-axis" at shallow pavement depths, but the differences are not significant at large depths, when dual tyres act as a unit load.

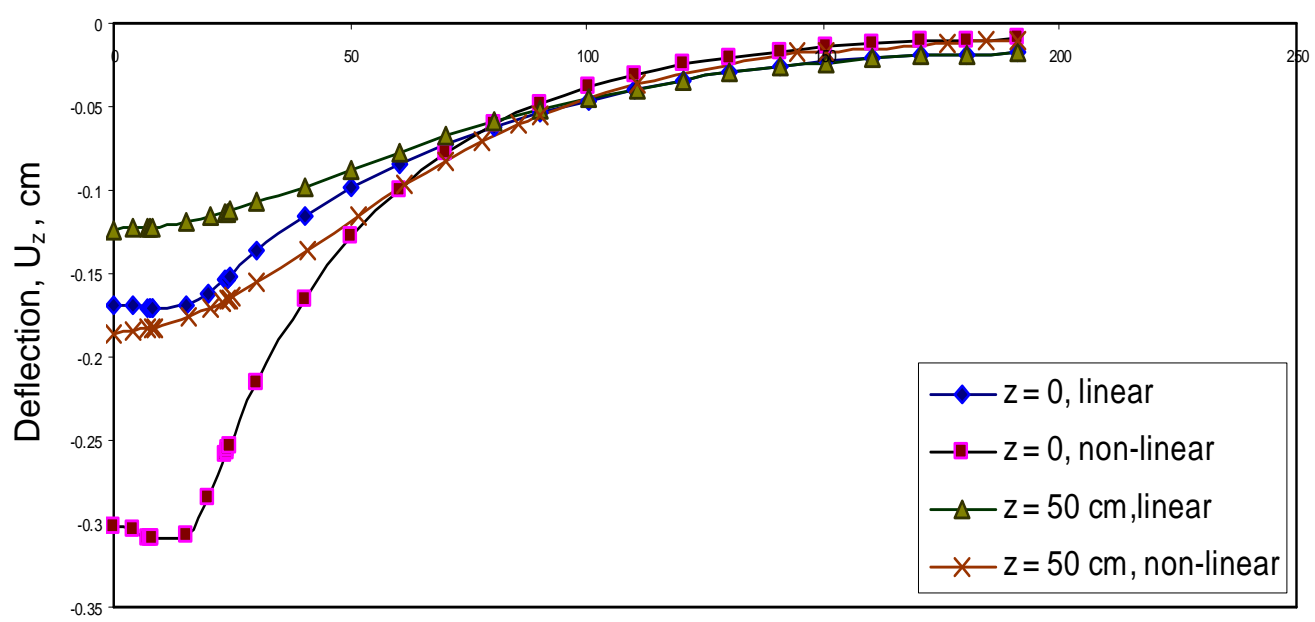

Distance, $\mathrm{cm}$

Fig. 15: Comparison of linear and non linear deflections of pavement surface and at depth of $50 \mathrm{~cm}$ through $\mathrm{x}$-axis.

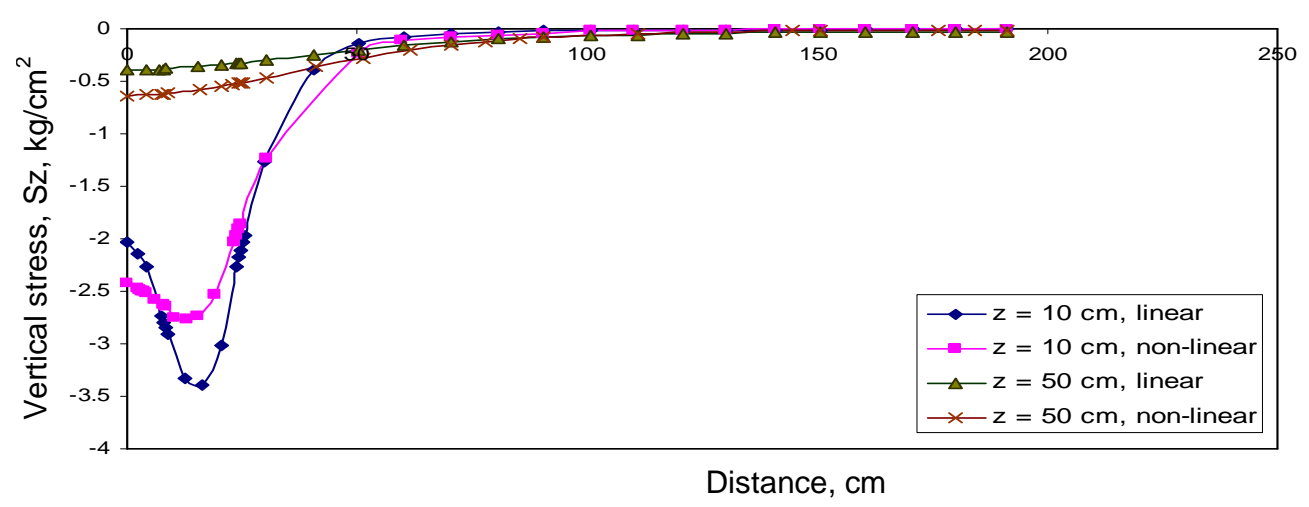

Fig. 16: Comparison of linear and non linear vertical stresses $\left(S_{z}\right)$ at depths of 10 and $50 \mathrm{~cm}$ through $\mathrm{x}$-axis. 
The different stresses $\left(S_{x}, S_{y}, S_{z}\right)$ at the bottom surface of lower surface layer are shown in photos given in photos 1a-1c in Appendix. So, the maximum shear tensile stress reached $1.4-1.86 \mathrm{~kg} / \mathrm{cm}^{2}$, while the vertical compressive stress is equal to $2.99 \mathrm{~kg} / \mathrm{cm}^{2}$ but, vertical compressive stress reached $0.56 \mathrm{~kg} / \mathrm{cm}^{2}$ at subgrade surface photo $1 \mathrm{~d}$ in Appendix. Photo 1e in Appendix illustrates that the pavement responses almost happen within semi-conical zone and sharply decreased beneath surface layer and extends to 2-3 times of wheel breadth roundly.

The amount of tyre pressure effect on pavement responses considering non linear analysis was performed. The increase of tyre pressure from 5.77 to $8.44 \mathrm{~kg} / \mathrm{cm}^{2}$ increases the deflection and stress through pavement for both linear and non linear analysis as shown in Figs. 17, 18. The pavement surface deflection is affected by wheel position as given in Fig. 17.

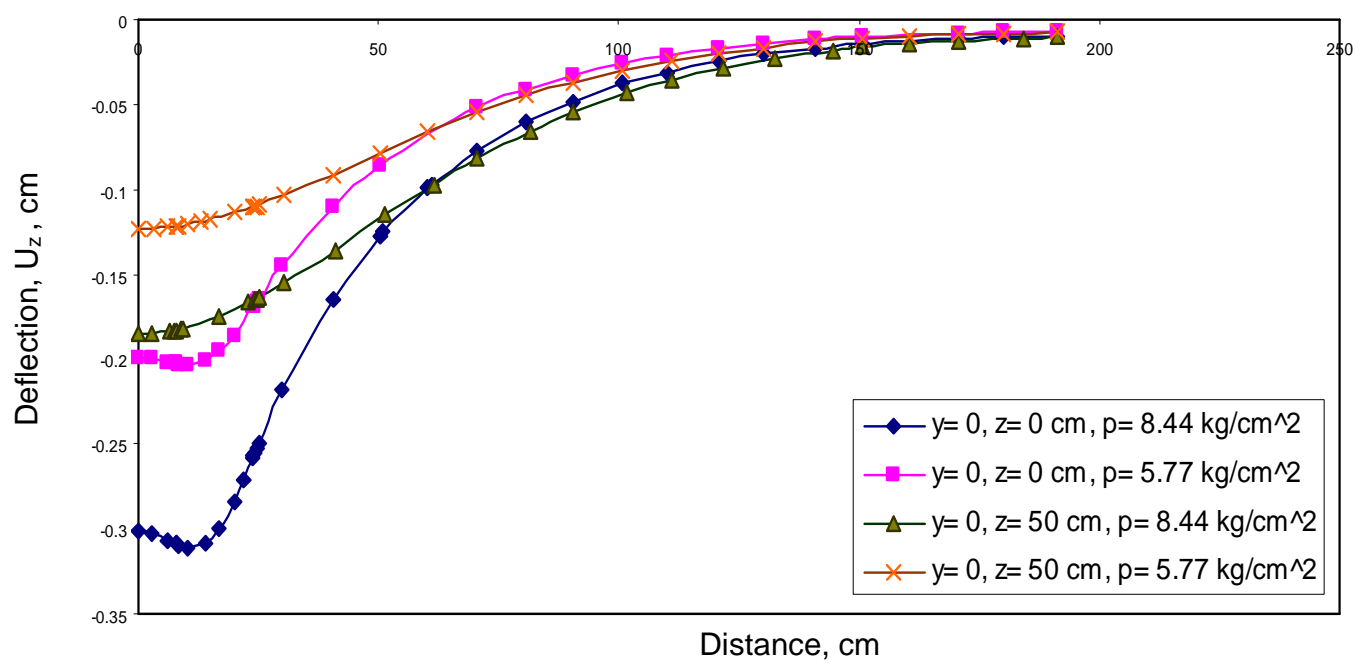

Fig. 17: Comparison of non linear deflections of pavement surface and at depth $50 \mathrm{~cm}$ through $\mathrm{x}$-axis due to different tyre pressure intensities.

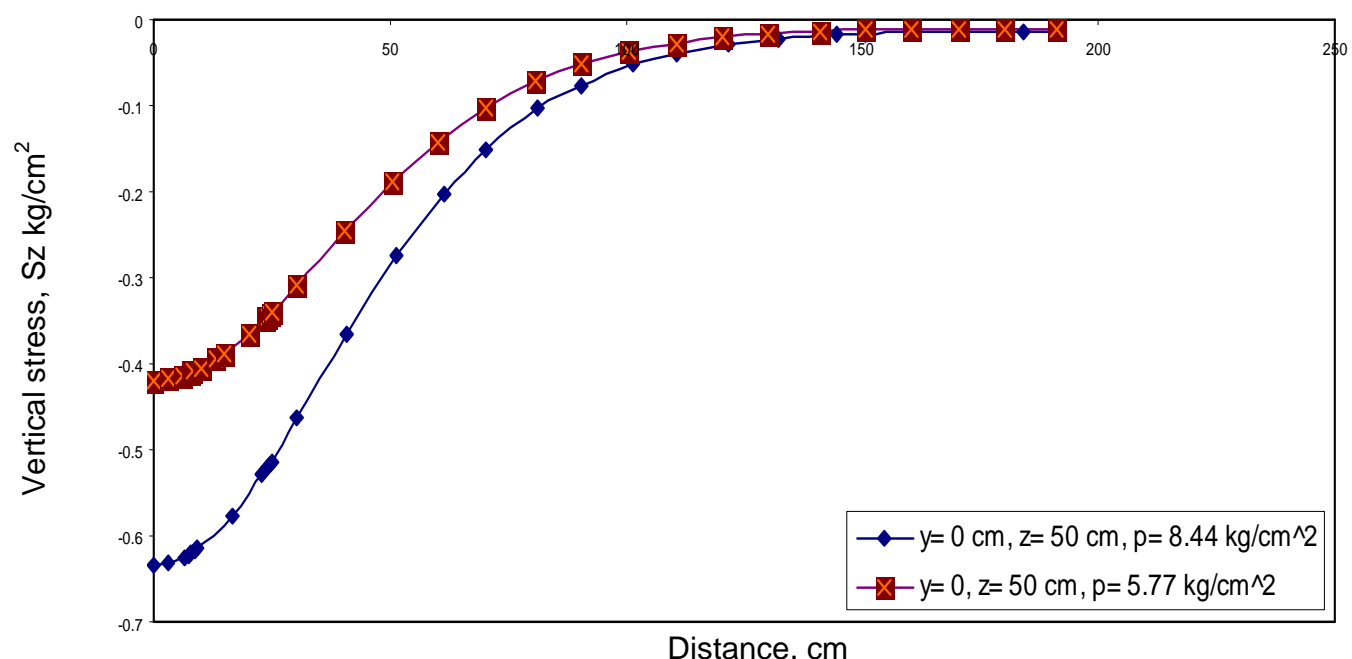

Fig. 18: Comparison of non linear vertical stress at depth of $50 \mathrm{~cm}$ through $x$-axis due to different tyre pressure intensities. 
The effect of wheel magnitude ranging between 8.2 and $9.3 \mathrm{t}$ with the same tyre pressure on pavement responses was performed. The deflections at surface and through pavement increase with increasing the magnitude of wheel load in spite of contact pressure equality as shown in Fig. 19. Also, the stresses through the pavement were increased owing to increasing wheel load as given in Fig. 20.

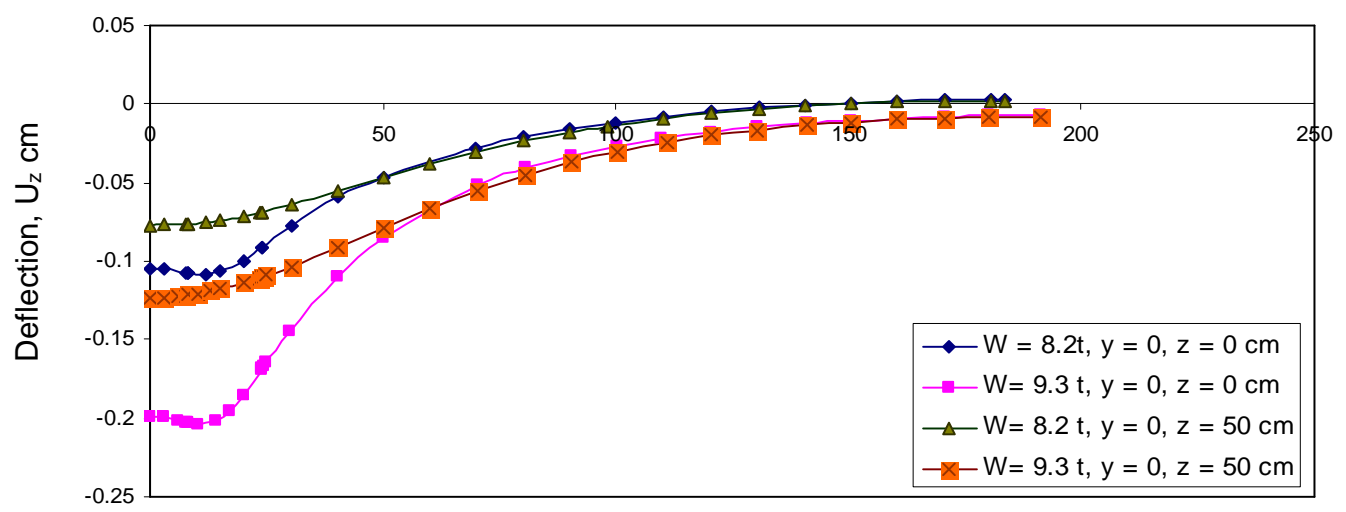

Distance, $\mathrm{cm}$

Fig. 19: Comparison of non linear deflections of pavement surface and at depth of $50 \mathrm{~cm}$ through $\mathrm{x}$-axis due to different wheel loading.

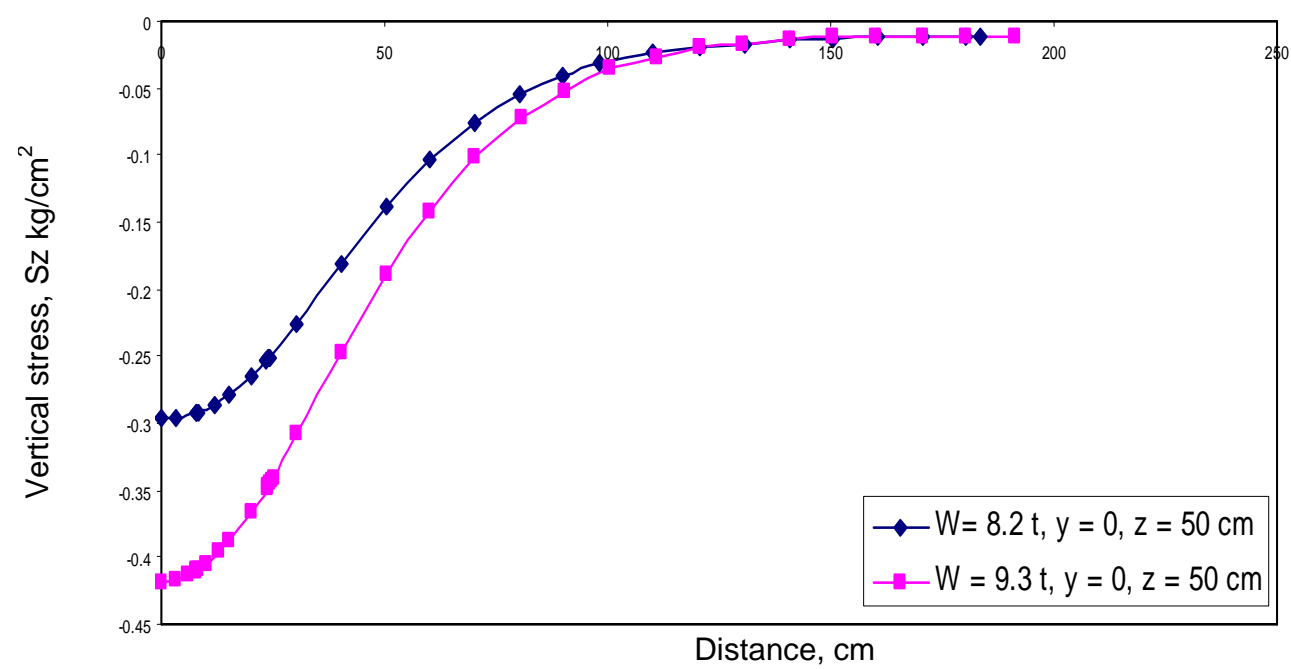

Fig. 20: Comparison of non linear vertical stress pavement depth of $50 \mathrm{~cm}$ through $x$-axis due to different wheel loading.

The surface layer rigidity effect on pavement responses due to tyre pressure equal to $5.77 \mathrm{~kg} / \mathrm{cm}^{2}$ was conducted considering non linear analysis. The deflection through pavement decreases with increasing of surface layer rigidity depending on pavement depth as shown in Figs 21-23. So, the deflection through $\mathrm{x}$-axis reflects the resulting equivalent wheel load through pavement and the resulting deflections are similar as those of Boussinesq's results. $\left(\mathrm{s}_{1}=\mathrm{s}_{1} \mathrm{n}\left(\mathrm{E}_{1}=30000 \mathrm{~kg} / \mathrm{cm}^{2}, \mathrm{E}_{2}=15000 \mathrm{~kg} / \mathrm{cm}^{2}, \mathrm{~s}_{2}=\mathrm{s}_{2} \mathrm{n}\right.\right.$ $\left(\mathrm{E}_{1}=20000 \mathrm{~kg} / \mathrm{cm}^{2}, \mathrm{E}_{2}=10000 \mathrm{~kg} / \mathrm{cm}^{2}\right), \mathrm{s}_{4}=\mathrm{s}_{4} \mathrm{n}\left(\mathrm{E}_{1}=10000 \mathrm{~kg} / \mathrm{cm}^{2}, \mathrm{E}_{2}=\right.$ $\left.5000 \mathrm{~kg} / \mathrm{cm}^{2}\right)$ ). 


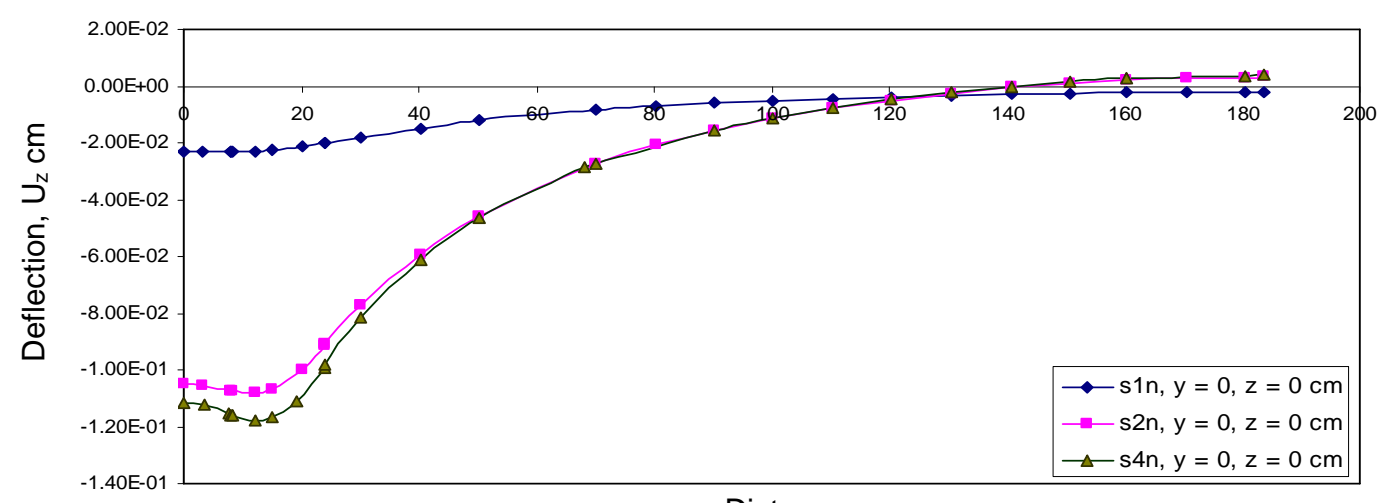

Distance, $\mathrm{cm}$

Fig. 21: Comparison of non linear deflection of pavement surface through $x$-axis for different surface layer rigidities.

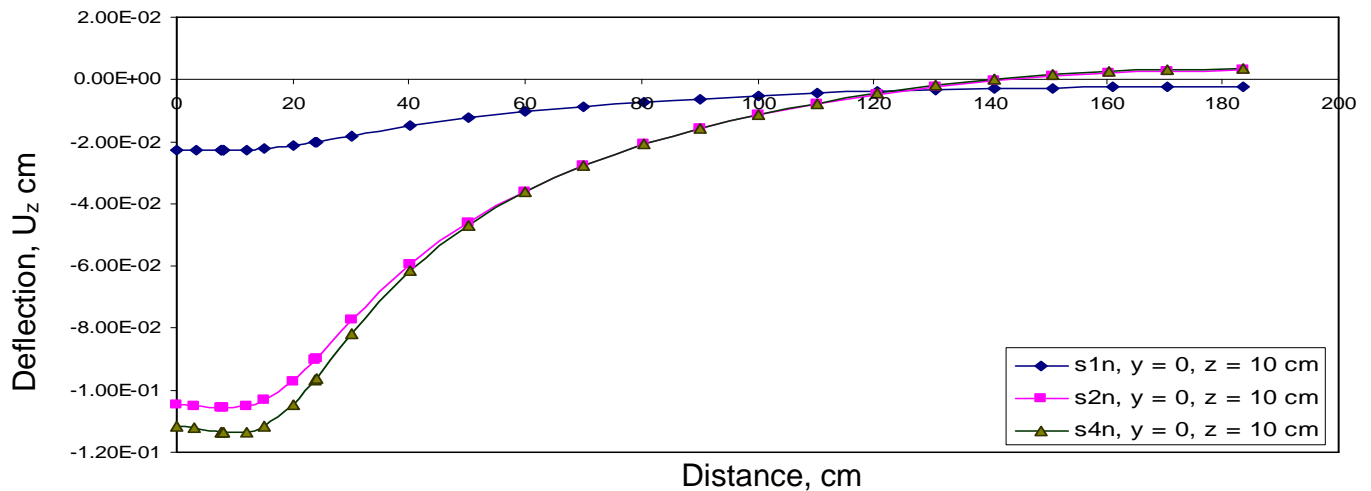

Fig. 22: Comparison of non linear deflection at pavement depth of $10 \mathrm{~cm}$ through $\mathrm{x}$ axis for different surface layer rigidities.

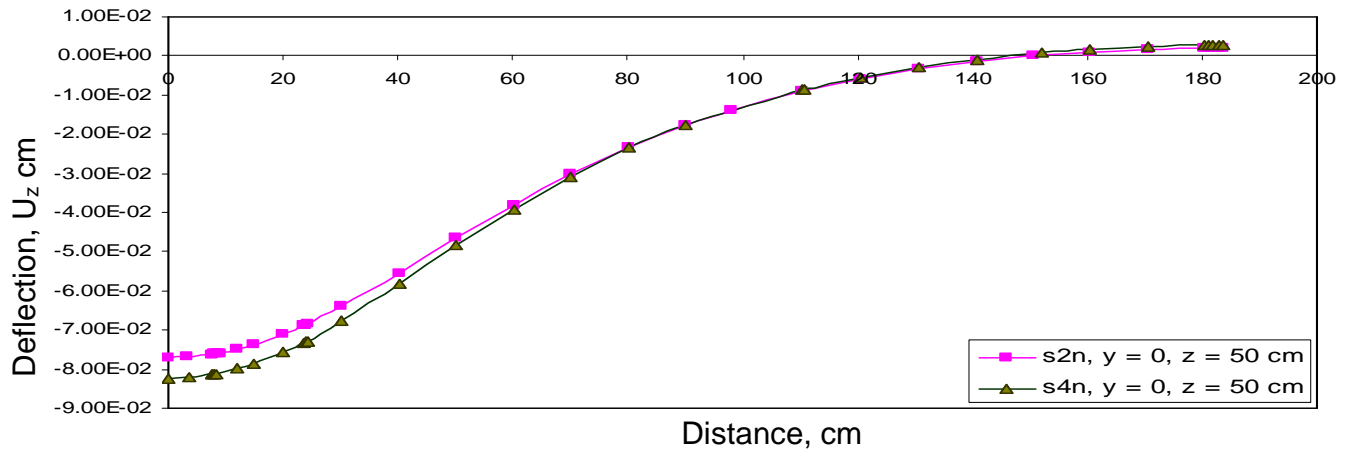

Fig. 23: Comparison of non linear deflection at pavement depth of $50 \mathrm{~cm}$ through $\mathrm{x}$ axis for different surface layer rigidities.

For non-linear analysis, the vertical stress at depths 10 and $50 \mathrm{~cm}$ through symmetry axis through (x-axis) is larger in case of lower surface layer rigidity especially through small depths as shown in Figs. 24, 25. On the other hand the tensile stress (tangential stress) is large through the load acting zone with high surface layer rigidity as given in Fig. 26. It may be owing to layer stiffness increasing and its proportioning with lower layer. 


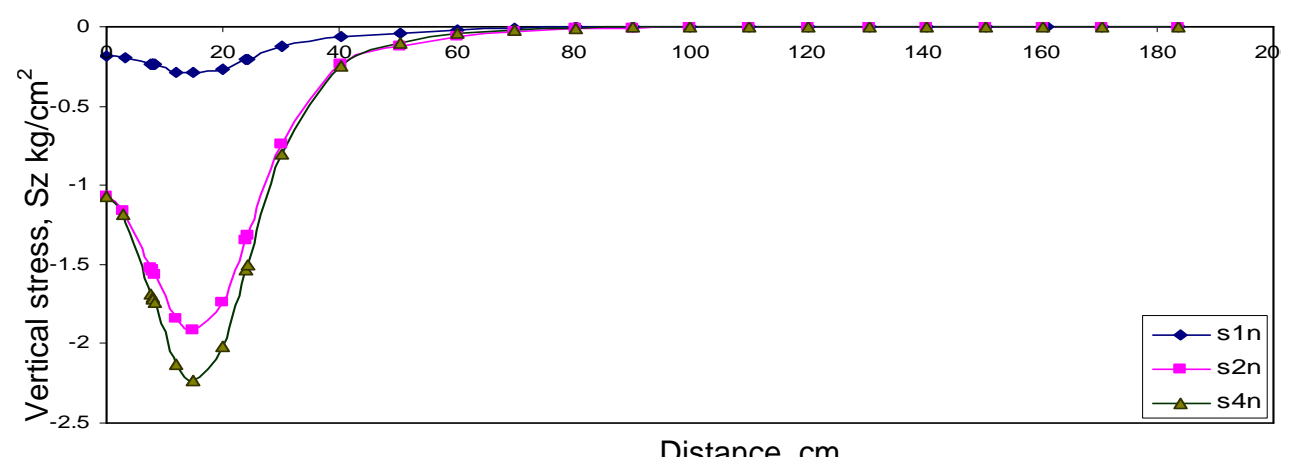

Distance, $\mathrm{cm}$

Fig. 24: Comparison of non linear vertical stress at pavement depth of $10 \mathrm{~cm}$ through $\mathrm{x}$-axis for different surface layer rigidities.

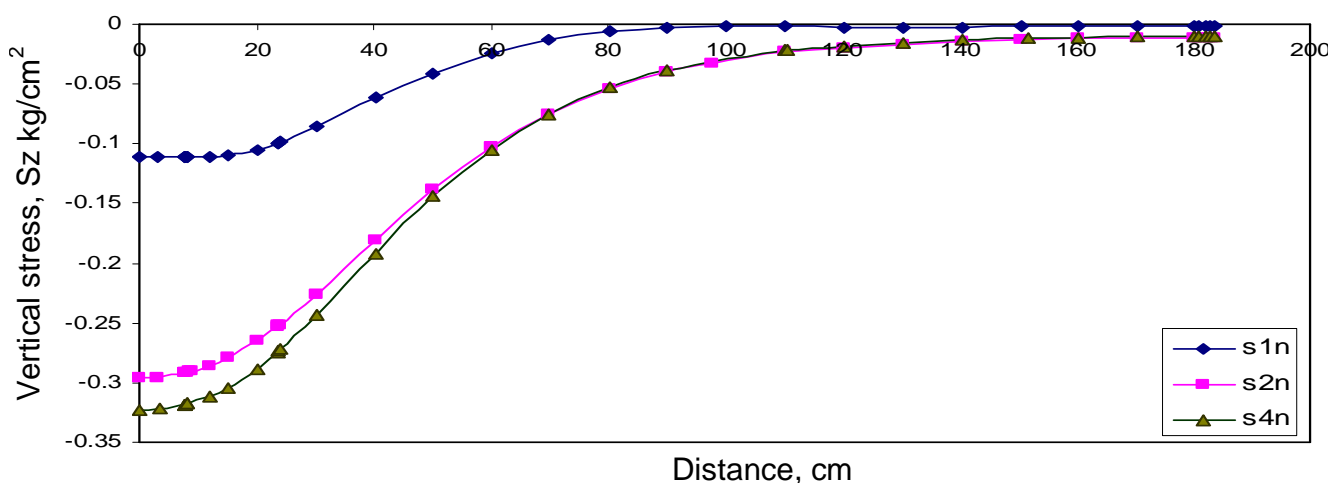

Fig. 25: Comparison of non linear vertical stress at pavement depth of $50 \mathrm{~cm}$ through $\mathrm{x}$-axis for different surface layer rigidities.

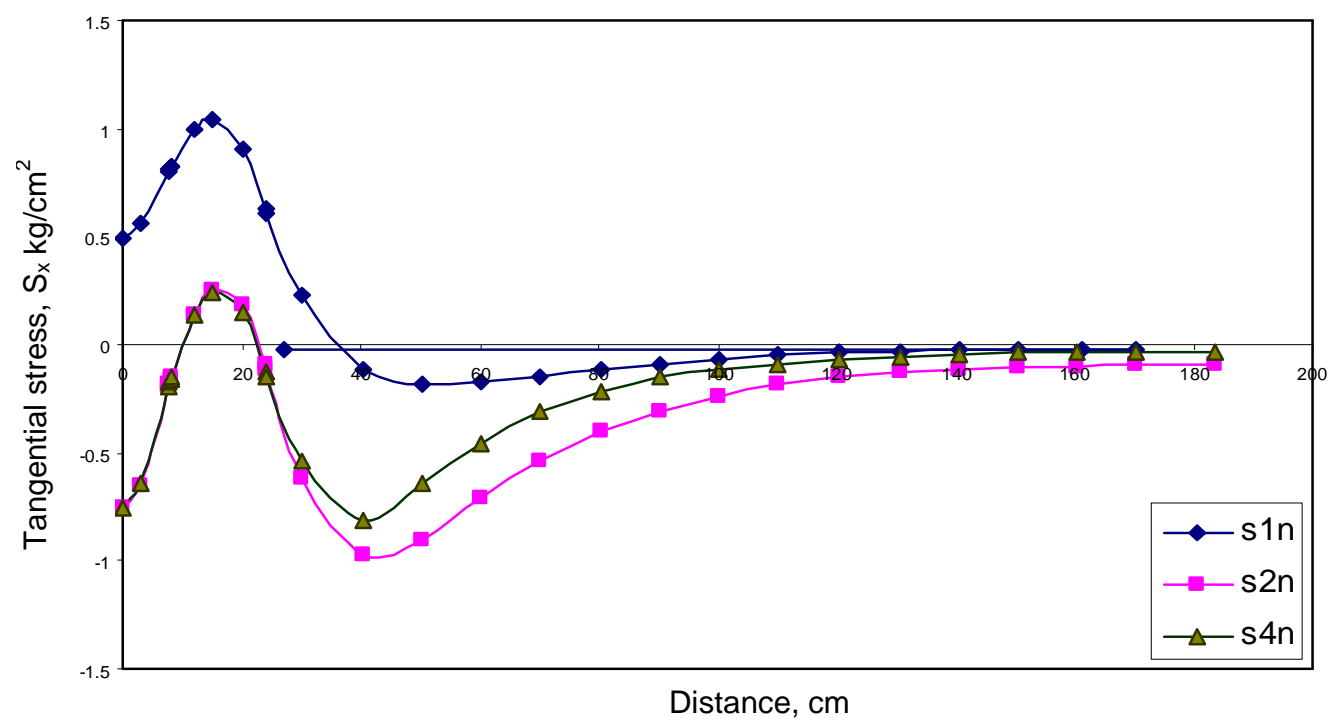

Figure 26 Comparison of non linear shear stress $S_{x}$ at pavement depth of $10 \mathrm{~cm}$ through $\mathrm{X}$-axis for different surface layer rigidities. 


\subsection{Effect Of Tyre Type On Pavement Responses}

The deflections and vertical stresses through planes of symmetry (y-axis), at subgrade due to different axle types as static load were obtained as presented in Figs. 27, 28. From these figures, it is noticed that the largest values of deflection and stress are obtained due to single tyre, while the smallest ones obtained when using dual tandemtyres. This may be attributed to the variable distribution of axle load at pavement surface. The maximum deflection at depth $50 \mathrm{~cm}$ using single tyre is $0.141 \mathrm{~cm}$, while it is equal to $0.106 \mathrm{~cm}$ due to dual tandem tyres. Also, the maximum stress obtained due to dual tandem-tyres equals $0.067 \mathrm{~kg} / \mathrm{cm}^{2}$, while it reached $0.135 \mathrm{~kg} / \mathrm{cm}^{2}$ for singletyre, i.e., the maximum deflection caused by the dual tandem configuration was approximately $27 \%$ less than that caused by the single tyre, while the vertical stress due to single-tyre reached $150 \%$ of that caused by the dual tandem-tyre configuration.

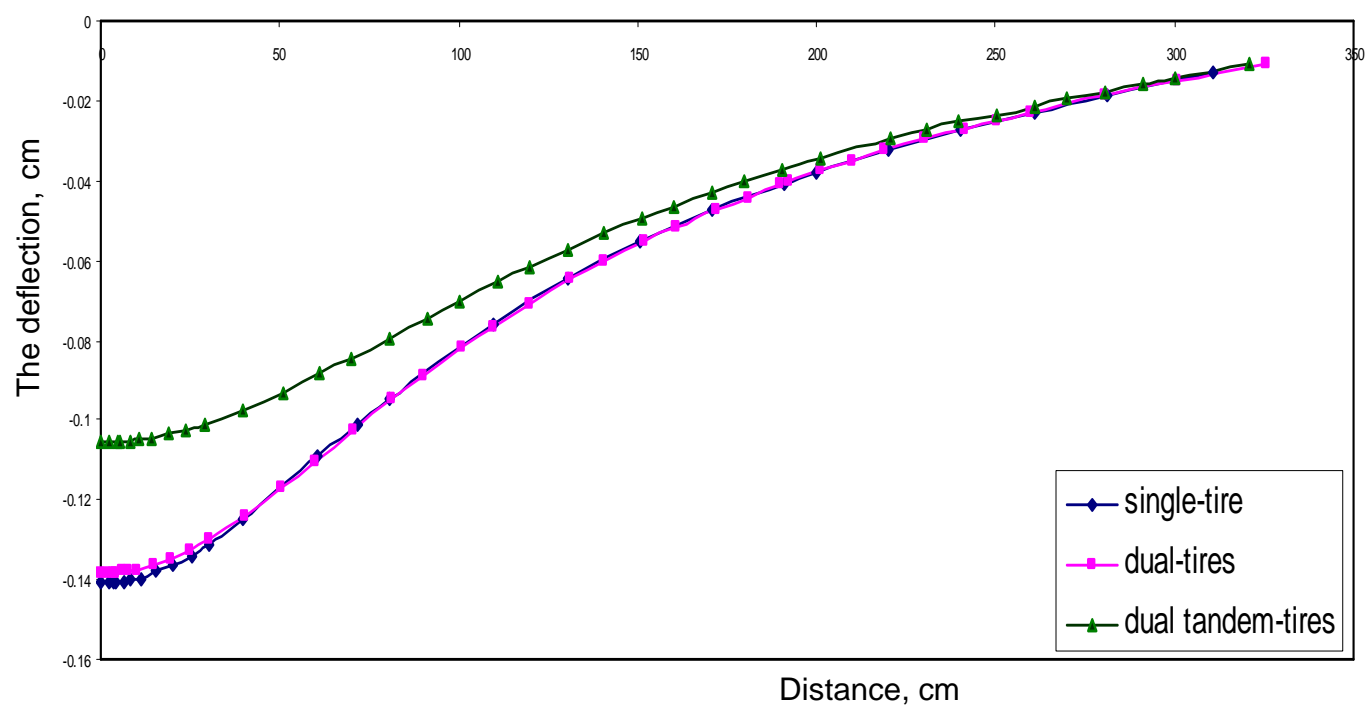

Fig. 27: The deflection at subgrade through plane of symmetry ( $Y$-axis) due to different wheel configurations.

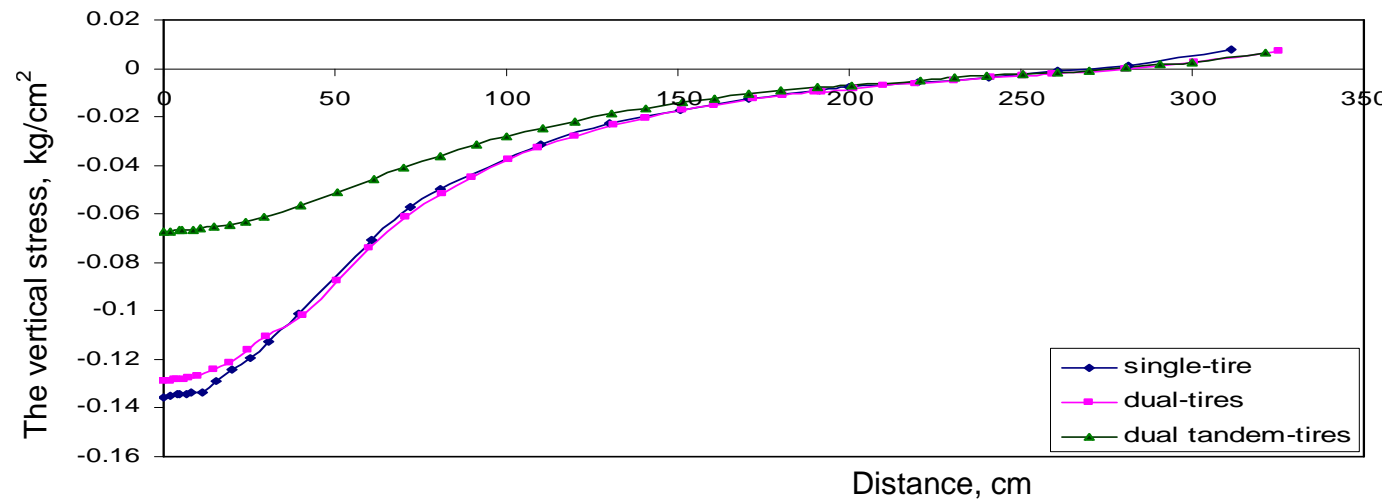

Fig. 28: The vertical stress at subgrade through plane of symmetry due to different wheel configurations. 
The vertical stress at the bottom surface of AC layer is shown in Fig. 29. So, the maximum compressive and shear tensile stresses occurred due to single tyre, while the smallest stresses happened due to dual tandem tyres. Therefore, it is expected that the more damage will be accomplished with trucks of single tyres than those with dual tandem tyres.

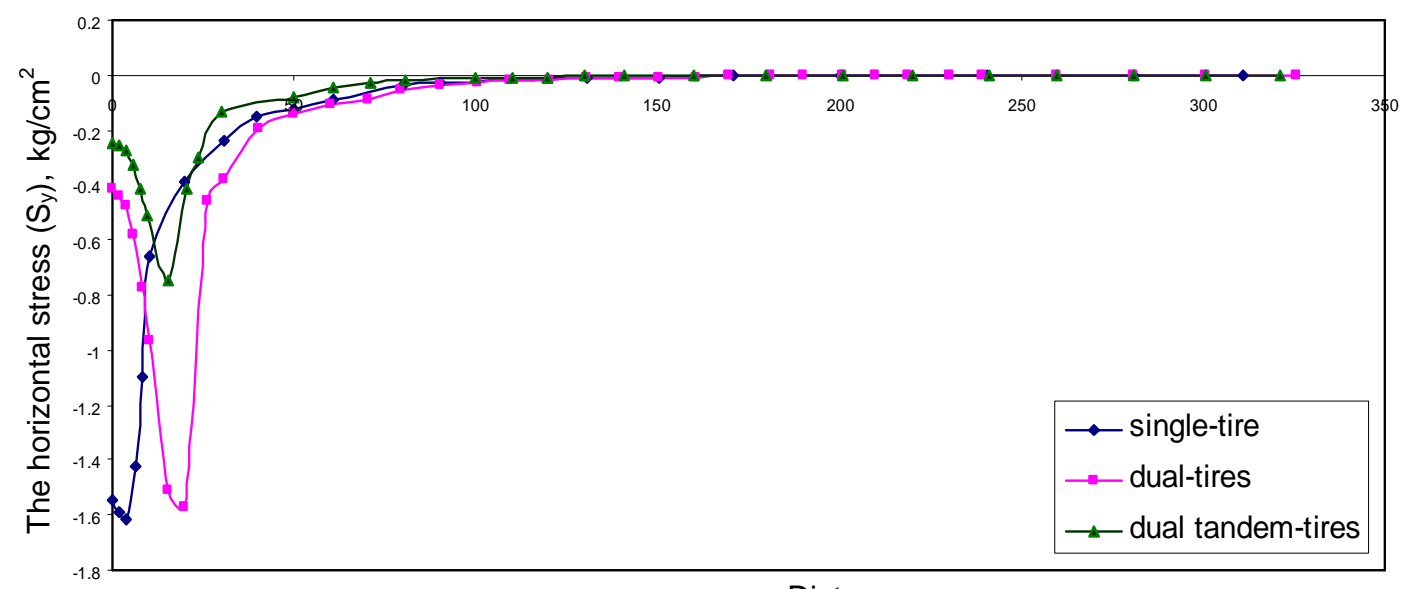

Distance, $\mathrm{cm}$

Fig. 29: The vertical stress at lower surface of $A C$ layer through plane of symmetry due to different wheel configurations.

\subsection{Effect Of Boundary Conditions On Pavement Responses}

The deflections through plane of symmetry (x-axis), at subgrade due to different situations and/or adhesion between pavement and shoulder were obtained as presented in Figs. 30. From this figure, it is noticed that the deflection in case of non complete adhesion between the pavement and shoulder and due to shoulder failure is higher than that obtained with tight adhesion of pavement and shoulder or in shoulder presence in the good case. This may be owing to shoulder strengthening effects on pavement performance, which increase road stability.

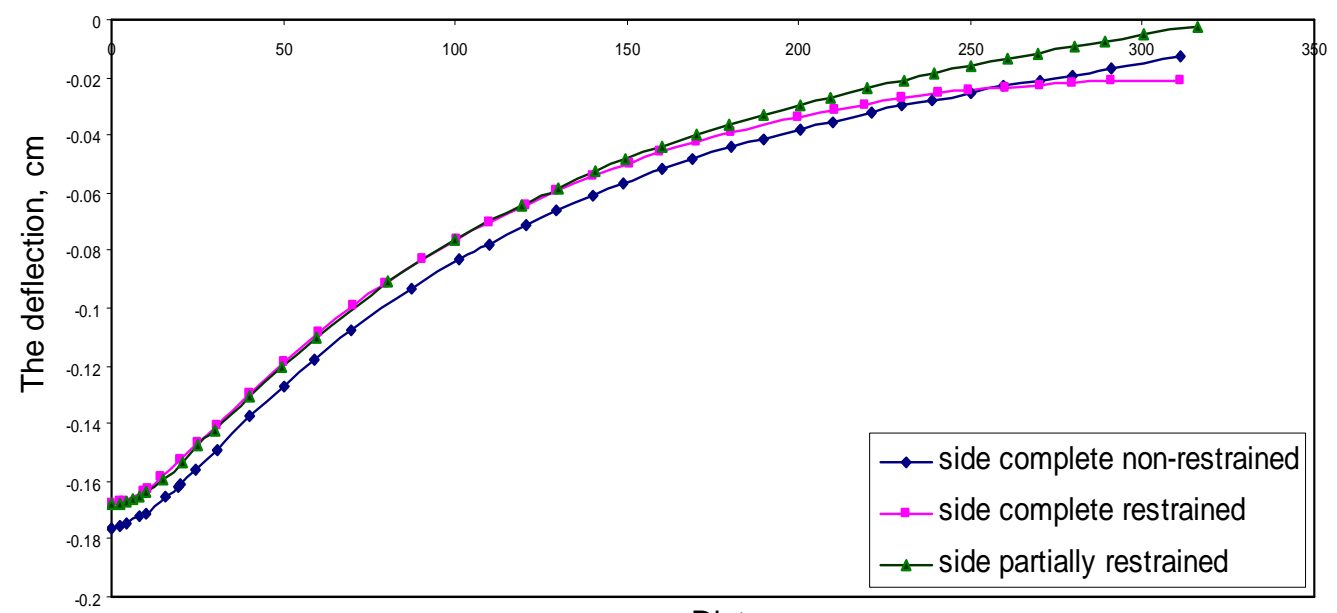

Distance, $\mathrm{cm}$

Fig. 30 The deflection at subgrade through plane of symmetry under different boundary conditions. 


\subsection{Effect Of Moving Wheel As A Harmonic Loads On Pavement Responses}

The shape and the maximum amplitudes of the responses along the moving coordinates do not necessarily occur at the same time due to the moving harmonic loads. When there is viscous damping, the maximum deflections are smaller than those without viscous damping as shown in Fig. 31. Also, with damping, frequency has a substantial effect on stresses and deflections as given in Figs. 32, 33. Figure A2 in Appendix illustrates how the pulses due to moving vehicle transmitted through the pavement. The vertical stress on subgrade is significantly affected due to vehicle motion as given in Fig. 34, but the deflection increases with small amount owing to increasing vehicle speed as shown in Fig. 35.

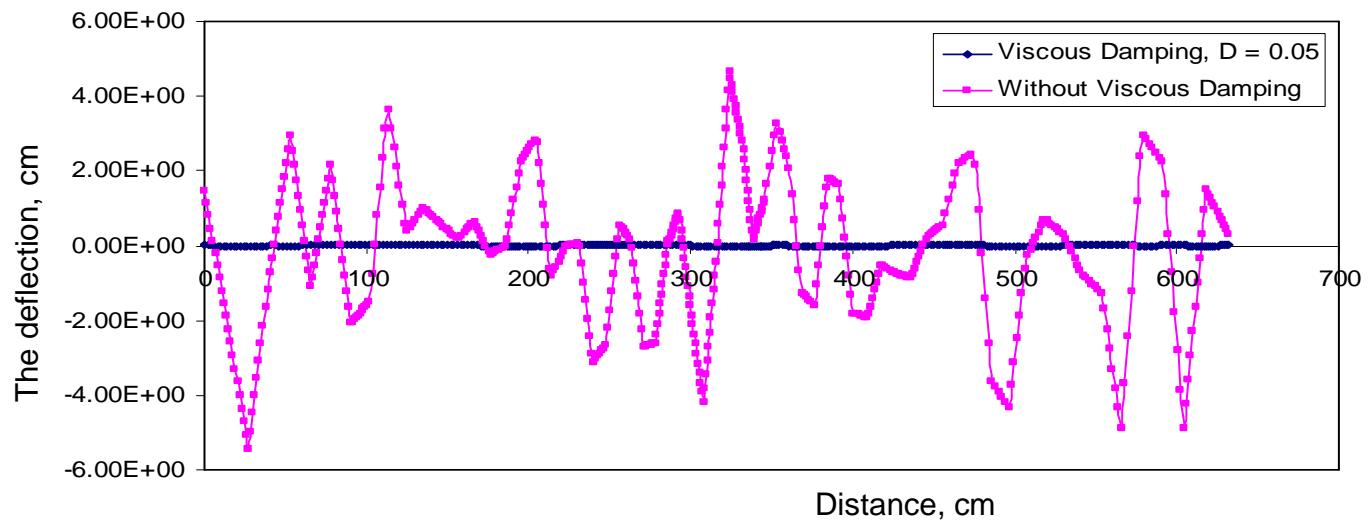

Fig. 31: The deflection distribution at subgrade through plane of symmetry due to different damping factor for load frequency $=10$ Hertz.

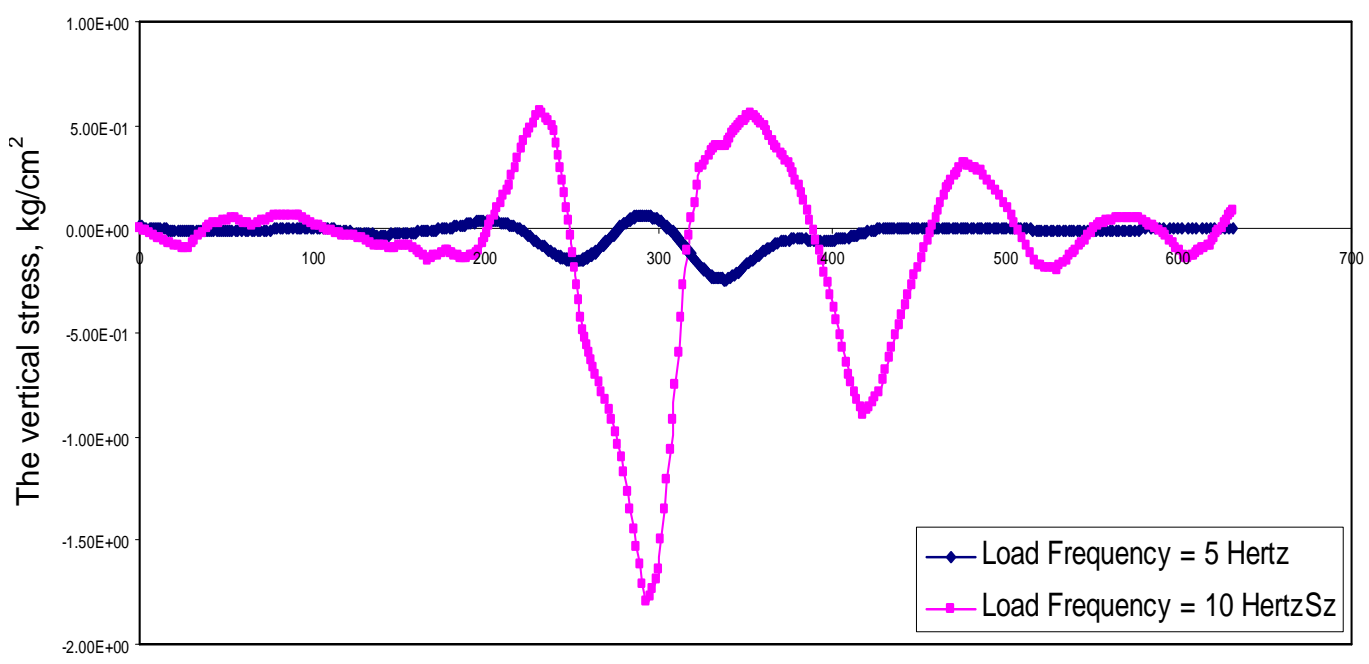

Distance, $\mathrm{cm}$

Fig. 32: The vertical stress distribution at subgrade through plane of symmetry due to different load frequency. 


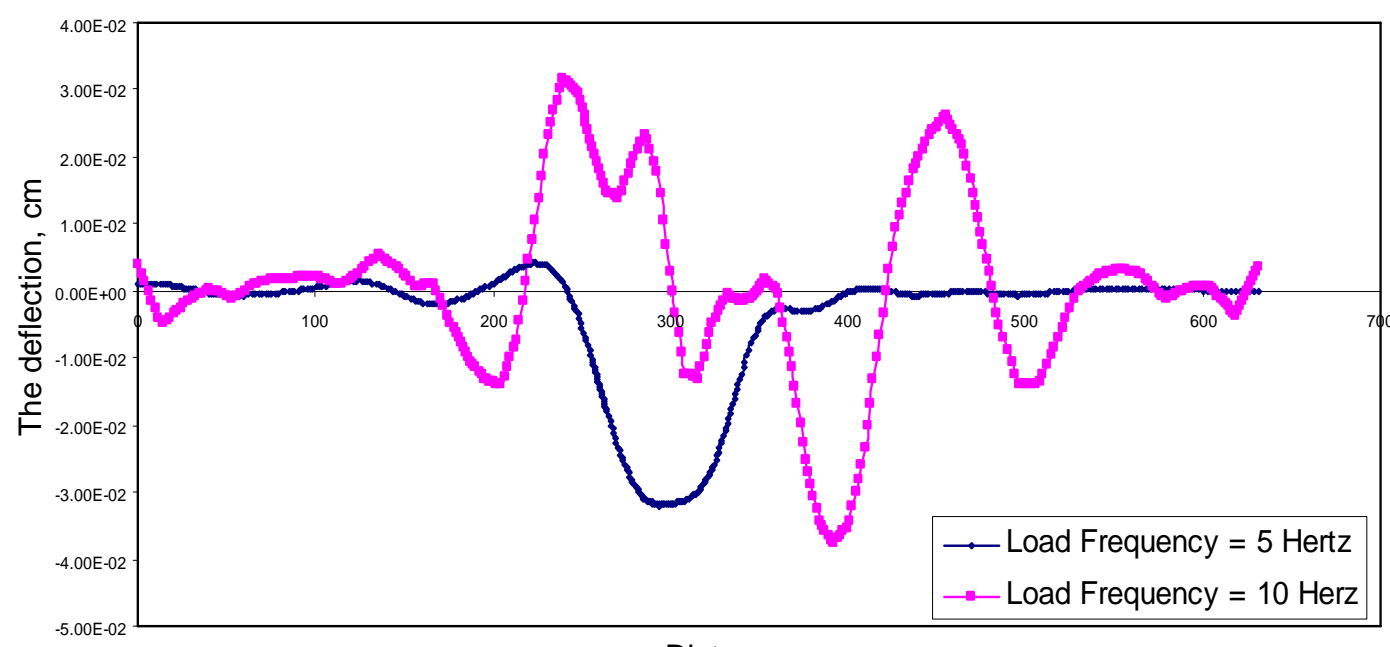

Distance, $\mathrm{cm}$

Fig. 33: The deflection distribution at subgrade through plane of symmetry due to different load frequency.

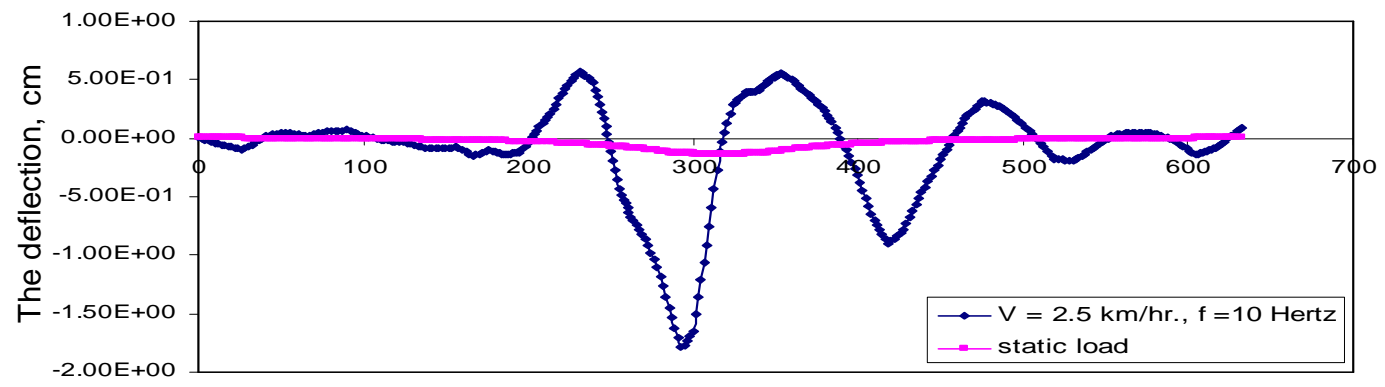

Distance, $\mathrm{cm}$

Fig. 34: The effect of vehicle speed on vertical stress at subgrade through plane of symmetry.

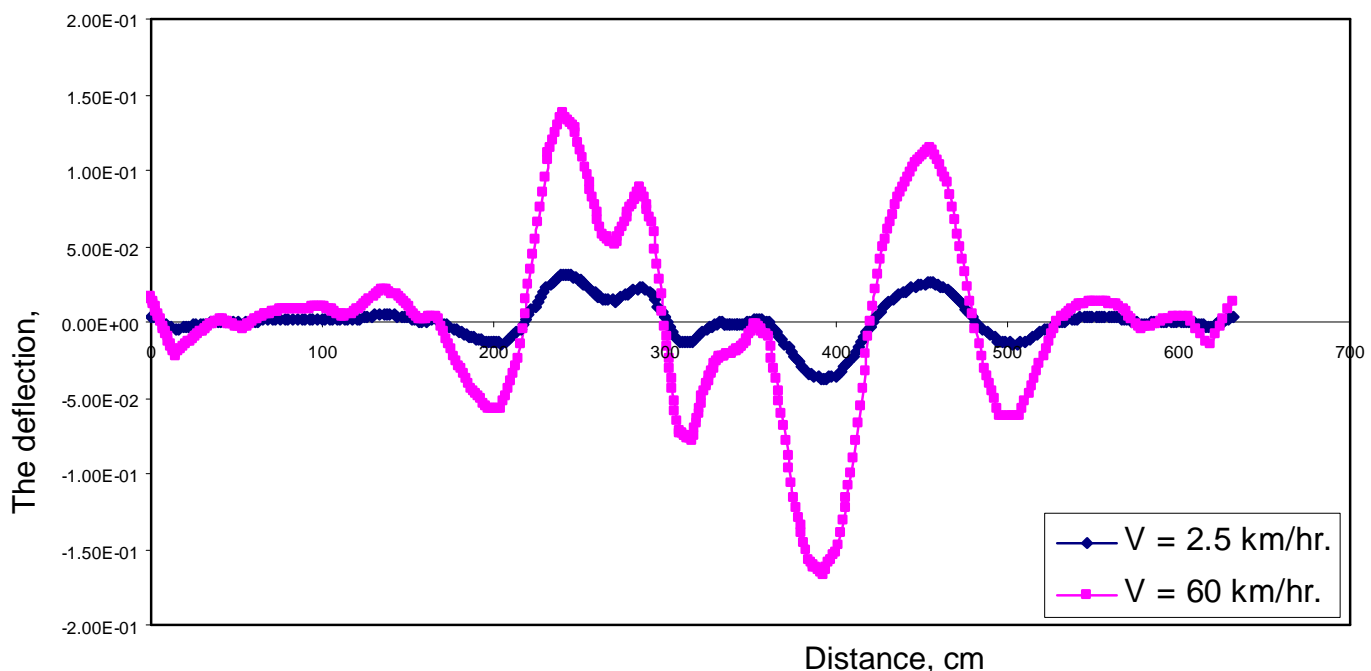

Fig. 35: The deflection at subgrade through plane of symmetry due to different vehicle speeds with load frequency $=10$ Hertz. 


\section{CONCLUSIONS}

1. The surface deflection and stress at shallow depths through C.L. of wheel are slightly greater than those at C.L. of wheel assembly configuration, but the difference is negligible at large depths.

2. For linear and non linear analyses, the deflection and the stress due to tyre pressure through pavement decrease as the depth from the surface increases.

3. The deflection curves through pavement depth reflect the concept of the resulting equivalent wheel load, which the assembled dual wheels may act.

4. For linear analysis, the maximum vertical stress according to the present analysis is equal to $130 \%$ of that obtained according to the modified Boussinesq's formula or by the 2-D analysis, while surface deflection is less by $10 \%$ than that obtained from the 2-D analysis.

5. The pavement responses almost happen within deficient conical zone and sharply decrease beneath surface layer and extend to 2-3 times of wheel breadth roundly.

6. The values of deflection and stress considering non linearity are greater than those obtained from the linear analysis.

7. For non linear analyses, the increase of tyre pressure increases the deflection and stress through pavement depending on pavement depth especially under the load acting zone. Those responses increase with increasing the magnitude of wheel load in spite of contact pressure equality.

8. The increase of surface layer rigidity decreases the resulting deflection and stress through pavement. Therefore, it is desirable to select surface layer of high quality and with enough thickness to resist tensile stresses exposed to the bottom surface of lower asphalt layer.

9. The primary response parameters (deflection and stresses) of the pavement caused by the dual tandem configuration were the smallest than those caused by the other tested tyre configurations. So, it is advisable or recommended to increase the axle load with dual tandem-tyres of traveling truck.

10. It is desirable to support pavement with shoulders to decreases the deformation, and stresses through pavement and early prevent its failure.

11. The deformations and stresses increased with increasing load frequency and the pulses transmitted through the pavement caused fatigue damage of its materials.

12. The moving wheel produces a higher deflection than the static loading and an additional contribution to deflection was noticed with increasing speed.

13. The current practice of pavement analysis using static loads can underestimate the maximum deflections and stresses, and the resulting pavement design can be less conservative

\section{REFERENCES}

[1] Per Ulidtz, "Pavement Analysis" Textest Book, Elsevier Science Publ. B.V, 1987.

[2] Roberts, F.L., Tielking, J.T., Middleton, D., Lytton, R.L., and Tseng, K. "Effect of Tyre Pressure on Flexible Pavements." Report No.372-IF, Texas Transp. Inst., College Station, Texas 1986.

[3] Kim O., and Bell C.A., "Effect of Increased Truck Tyre Pressure on Asphalt Concrete Pavement" Jour. Transp. Eng., Vol. 115, No. 4, PP. 329-352, 1989. 
[4] Sebaaly P.E., Tabatabae, N., "Effect of Tyre Parameters on Pavement Damage and Load-Equivalency Factors" Jour. Transp. Eng., Vol. 118, No. 6, PP. 805819, 1992

[5] Brown S.F., "Achievements and Challenges in Asphalt Pavement Engineering" ISAP- ${ }^{\text {th }}$ International Conference on Asphalt Pavements - Seattle, 1997.

[6] Freeman R.B. and Harr M.E., "Stress Prediction for Flexible Pavement Systems" J. Transp. Engrg., Vol.130, Issue 7, pp.495-502, 2004.

[7] Hadi M.N.S., "Non-linear Finite Element Analysis of Flexible Pavements", Advance Engineering Software, 34, 2003, PP. 657-662.

[8] Abd Alla E.M., "Simplified Method for Flexible Pavement Design Using Finite Element Method (FEM)", Bulletin of the Faculty of Eng., Assiut University, Vol. 25, No. 2, July 1997.

[9] Abd Alla E.M., "Flexible Pavement Design Using Deflection Criterion", Bulletin of the Faculty of Eng., Assiut University, Vol. 26, No. 1, January 1998.

[10] 10 Abou-Ahmed K.A., "Design of Flexible Pavements as a Function of Subgrade Bearing Capacity", $1^{\text {st }}$ Alexandria Conference on Structural and Geotechnical Engineering, 1-3 December 1990.

[11] Bonaquist, R., Churilla, C. and Freund, D., "Effect of Load, Tyre Pressure, and Tyre Type on Flexible Pavement Response." Transp. Res. Record, (1227), 1989, PP.97-106

[12] Park, S-W; Lytton, RL, "Effect of Stress-Dependent Modulus and Poisson's Ratio on Structural Responses in Thin Asphalt Pavements" Journal of Transportation Engineering, Volume: 130 Issue: 3, 2004, PP 387-394, Reston, USA

[13] Kim D., Salgado R. and Altschaeffi A. G., "Effects of Super-single Tyre Loadings on Pavements" J. Transp. Engrg., Vol.131, Issue 10, pp.732-743, 2005.

[14] Mamlouk M.S. and Davies T.G., "Elasto-Dynamic Analysis of Pavement Deflections" Jour. of Transp. Eng., Vol. 110, No. 6, Nov. 1984.

[15] Moriyoshi A., Partl M. N., Denpouya H. and Takano S., "Damage Analysis for Flexible Pavement at High Temperatures Using Visco-elastic Hybrid FEM", Master Science paper, faculty of Eng. , Hokkaido University, Japan, 2002.

[16] Sebaaly P.E. and Mamlouk M.S. "Development of Dynamic Fatigue Failure Criterion." Jour. of Transp. Eng. Vol. 114, No. 4, July 1988.

[17] Seong-Min Kin., B. Frank McCullough, "Dynamic Response of Plate on Viscous Winkler Foundation to Moving Loads of Varying amplitude" Eng. Structures 25, 2003,1179-1188.

[18] Helwany S.,Dyer J. and Leidy J., "Finite-Element Analysis of Flexible Pavements" Jour. of Transp. Eng., PP. 491-498, 1998.

[19] White T.D., Zaghloul S.M., Anferton G.L., and Smith D.M., "Pavement Analysis for Aircraft Load" Jour. of Transp. Eng., PP. 436-446, 1997.

[20] Saltan M. and Sezgin H., "Hybrid Neural Network and Finite Element Modeling of Sub-base Layer Material Properties in Flexible Pavements" Jour. of Materials and Design, February, 2006.

[21] ANSYS Program, Vergion-8, SAS IP, Inc1 Second Edition, 1996

[22] Enieb M.O., "Elasto-Plastic Critical State Model with Strain Localization in soil Structures", Ph.D. dissertation, University of Innsbruck, Austria, 2004. 


\section{Appendix}

sx

RSYS $=0$

$\mathrm{DLX}=.31085$

SMD $=-3-67$

SMX $=1.99$

Photo 1a: $S_{x}$
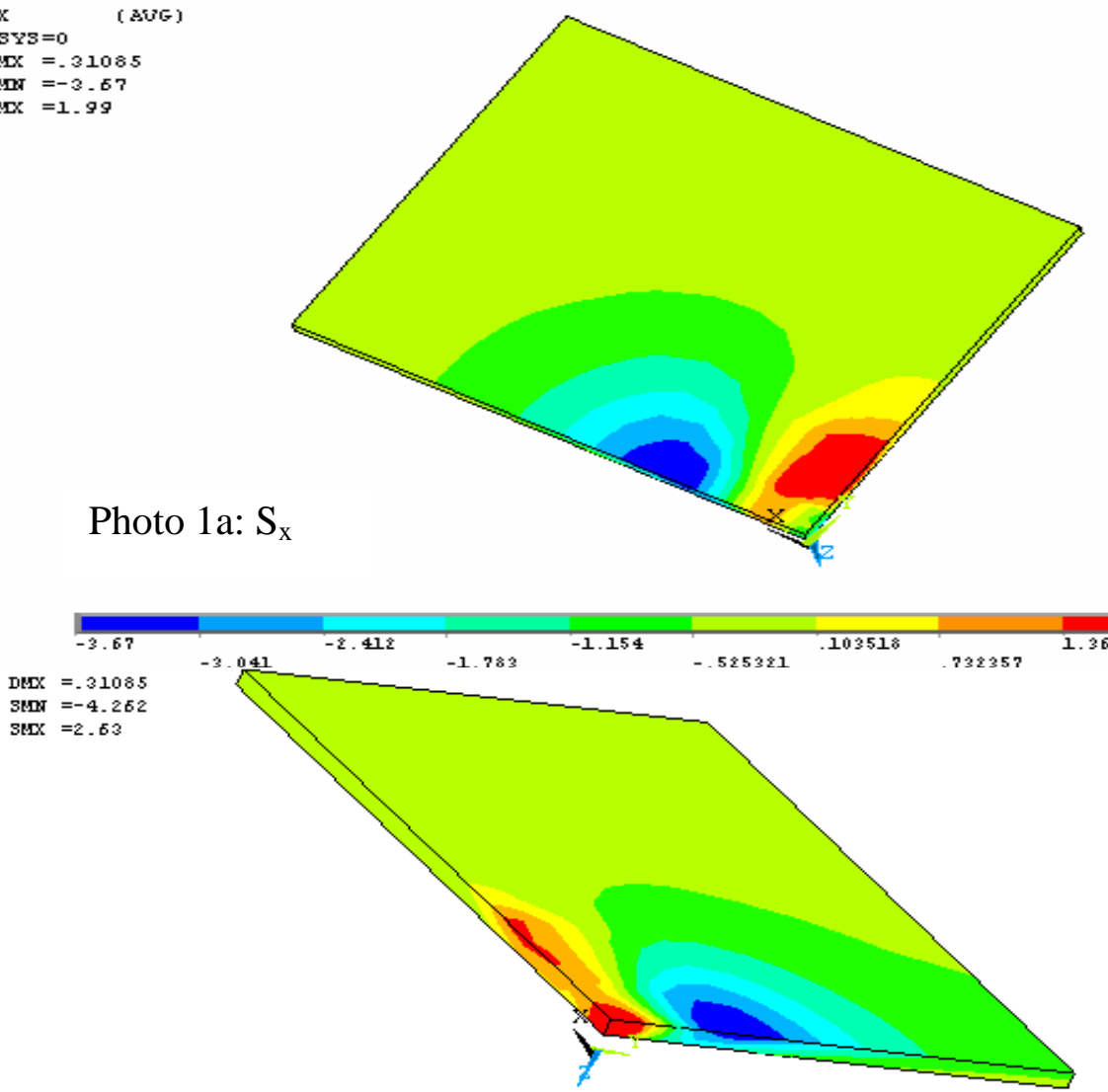

Photo 1b: $\mathrm{S}_{\mathrm{y}}$

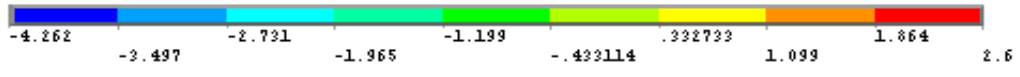

DUNU $=-31085$
SMD $=-3.862$

SMD $=-3.862$
$\operatorname{SEX}=.05638$

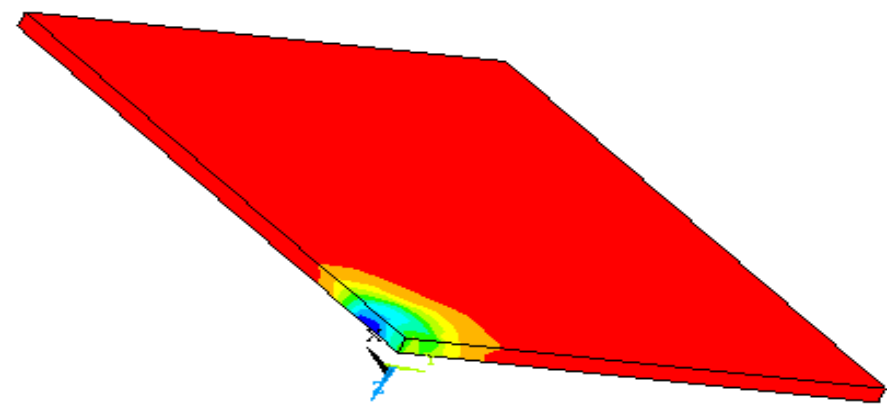

Photo 1c $S_{z}$

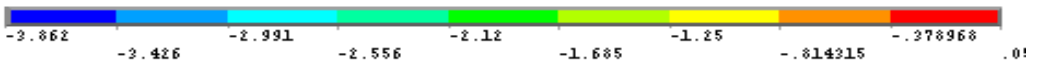


MODAI SOLUT ION

STEP $=1$

SUB $=15$

T IMIE $=100$ ( AUG

$\mathrm{Sz}$
$\mathrm{RSYS}=0$

$\mathrm{Dex}=-185447$

$\sin =--257758$

$\operatorname{sex}=-010634$

photo1d: $\mathrm{S}_{\mathrm{Z}}$ at $\mathrm{Z}=50 \mathrm{~cm}$
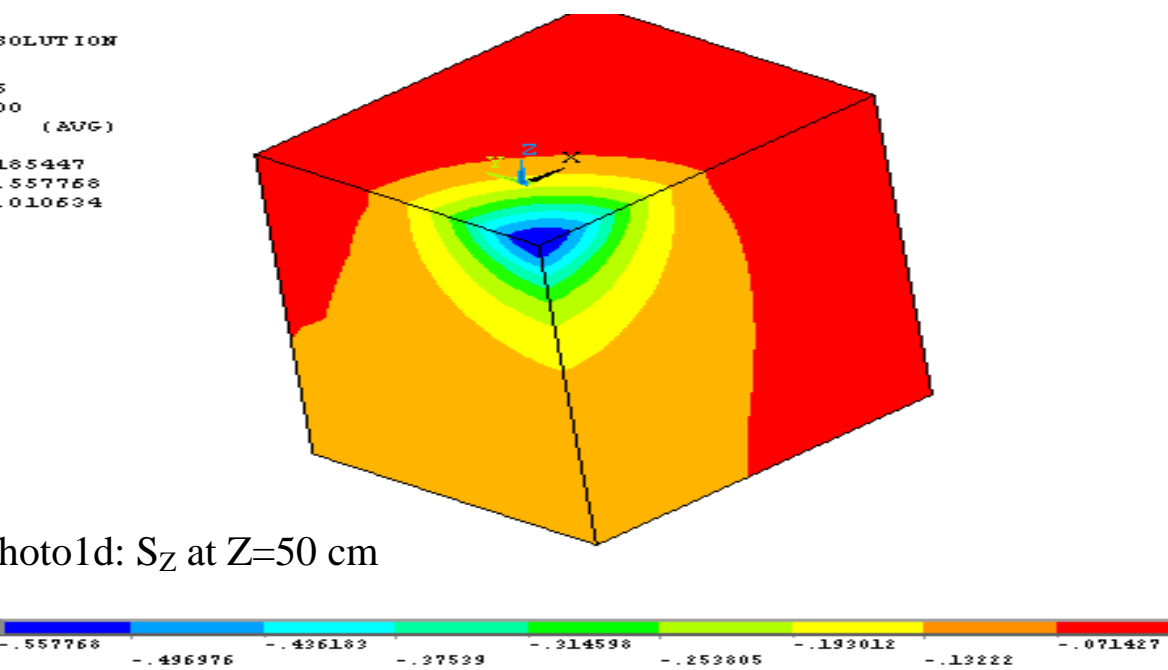

sus $=\cdot r$

T IME $=21.781$

sz

RSYS $=0$

$\operatorname{Dex}=-052424$

$\operatorname{sex}=.169$

photo1e: $\mathrm{S}_{\mathrm{Z}}$ trough pavement
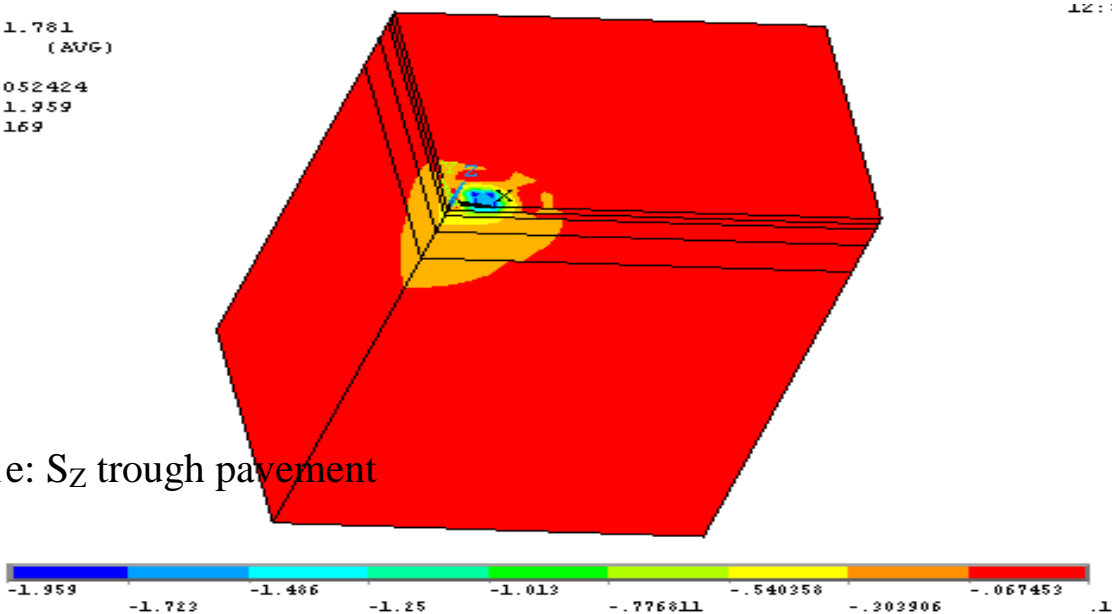

Fig. A1: Non linear stresses at bottom of surface layer and through pavement.

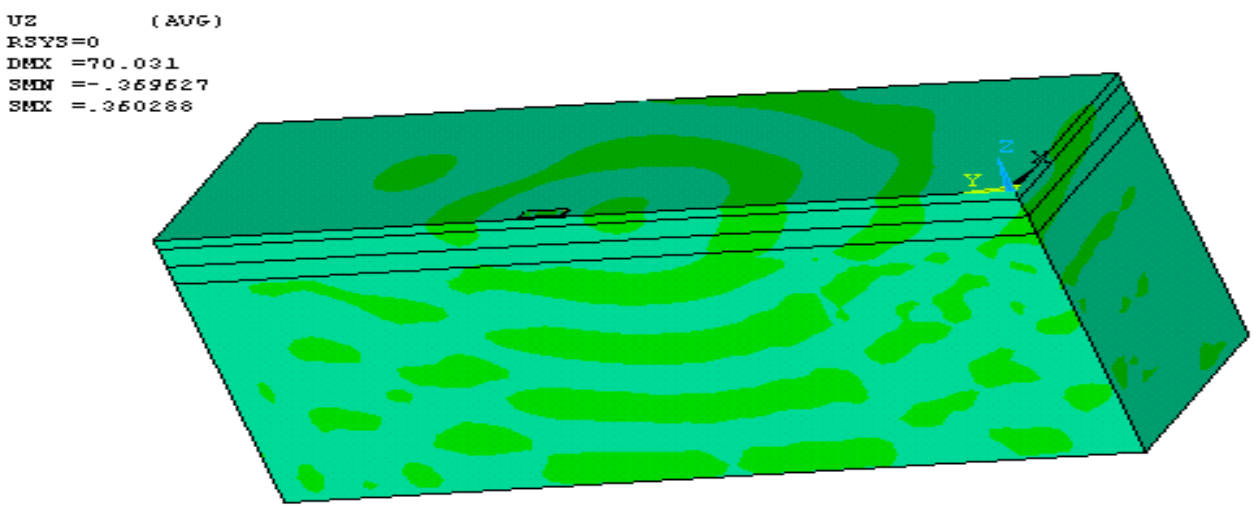

Fig. A2: The deflection pulses distribution through pavement due to a moving tyre with load frequency $=5$ Hertz 


\section{الاستخدام المنطقي لطريقة العناصر المحددة في التحليل للرصف المرن}

الظروف البيئية والأحمال المرورية وخو اص مو اد الرصف وطرق الإنشاء تعتبر من العو امل

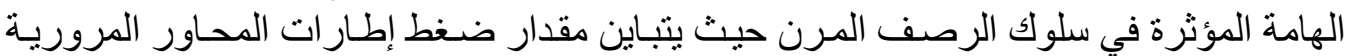

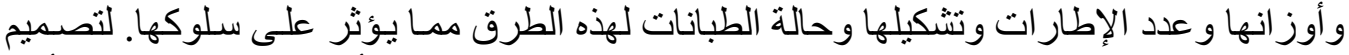

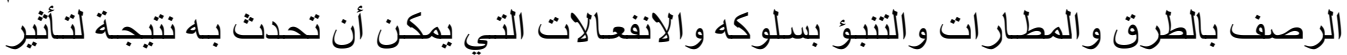

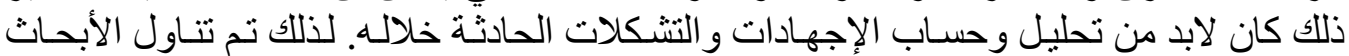

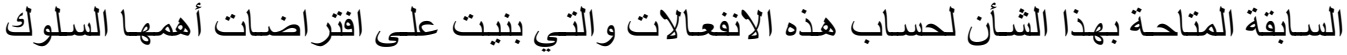

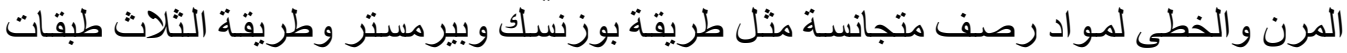

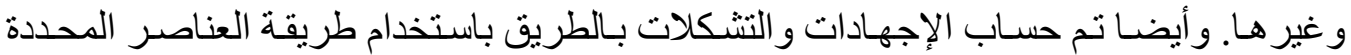

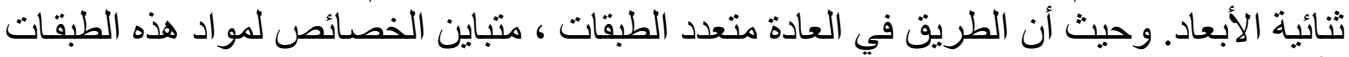

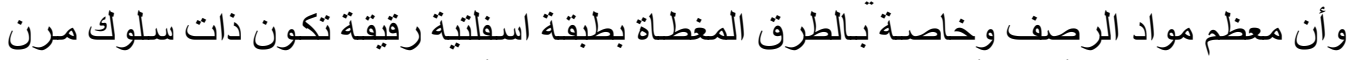

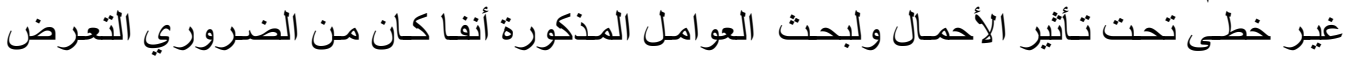

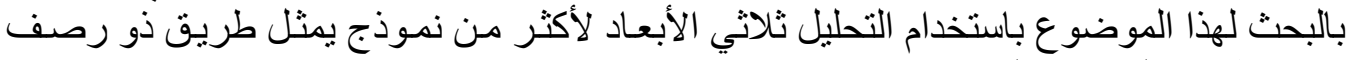
مرن بطريقة العناصر المحددة.

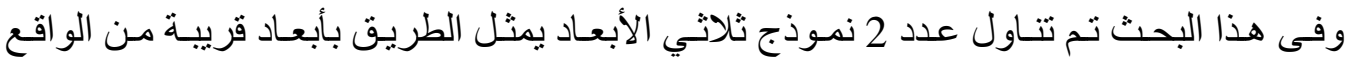

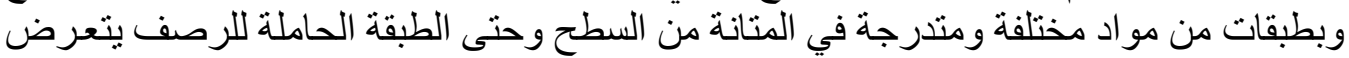

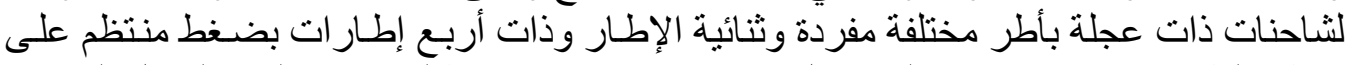

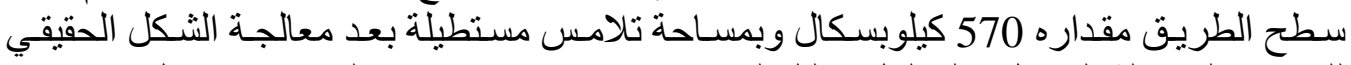

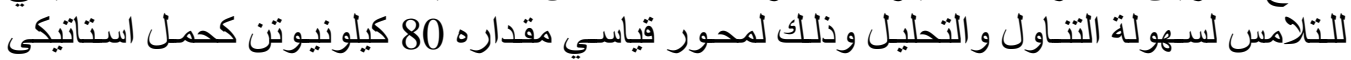

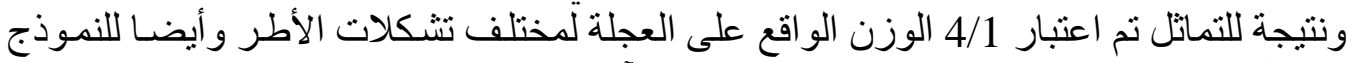

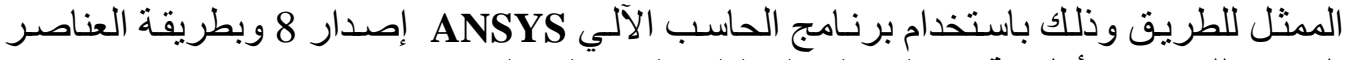
المحددة للنموذج الأول وقد تم التناول بالتحليل والبحث لمان لما يلي:

1- الإجهادات و التشكلات بطبقات الرصف باعتبار سلوكها مرن وخطيا.

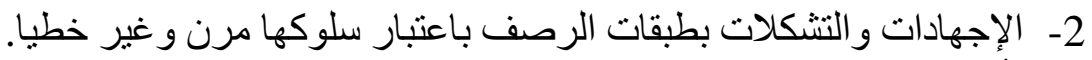

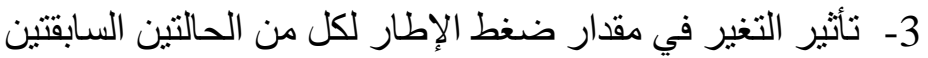

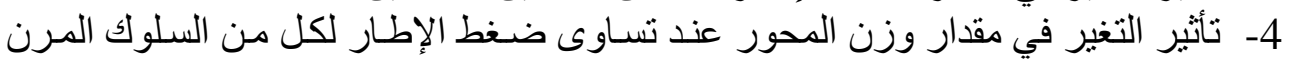

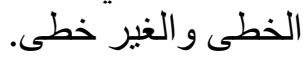

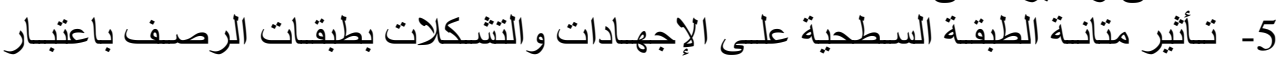
سلوكها مرناغير خطيا. وباستخدام برنامج الحاسب الآلي ANSYS إصدار 10 وبطريقة العناصـر المحددة للنموذج دئي

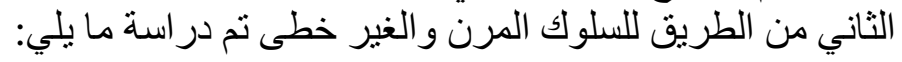

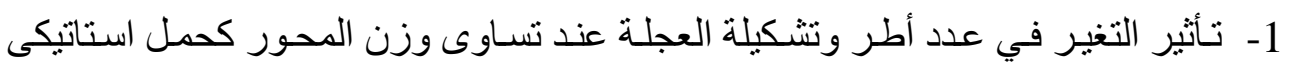
وضغط الإطار. 2- تأثثير وجود الطبانات وجودتها على التشكلات و الاجهادات خلال الطريق لنفس المحور

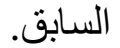

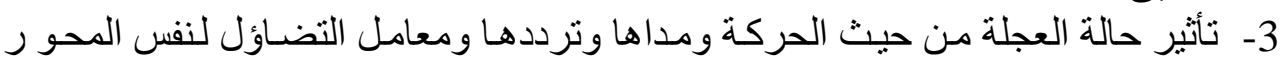

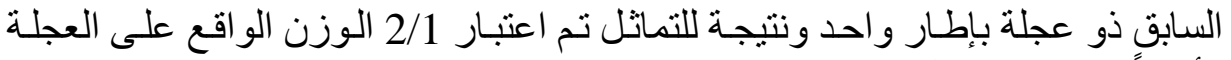
و أيضاً للنموذج الممثل للطريق. 


\section{وقد تم مناقشة وتحليل النتائج المنبثقة واستخلاص عدة نتائج من البحث أهمها:}

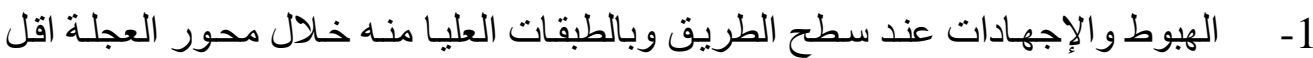
بدرجة ما عنه خلال محور الإطار الواحد ويتلاشى هذا الفرق كلما زاد البعد عن سطح

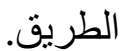

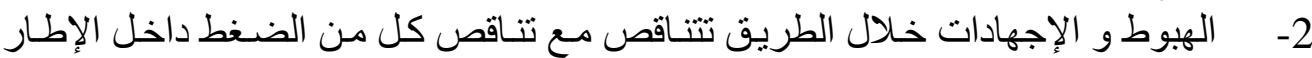
وزيادة البعد عن سطح الطريق.

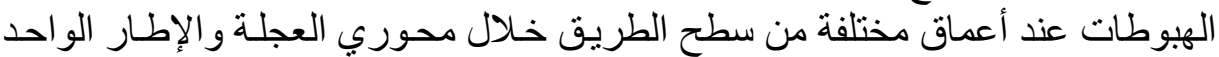

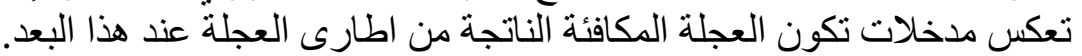

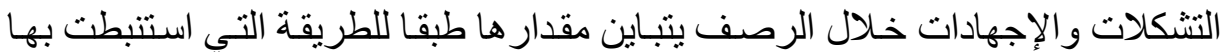

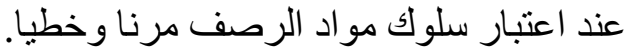

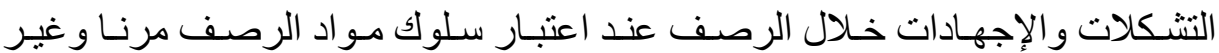

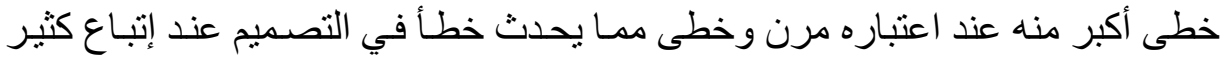

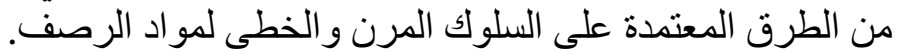

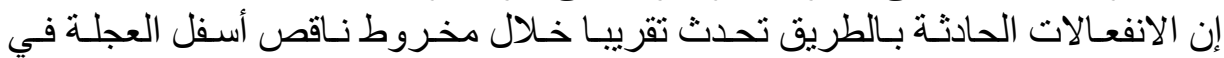

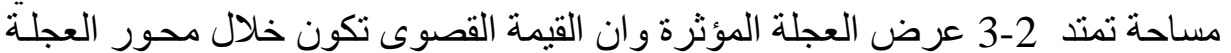
بالطبقات السفلى من الرصف.

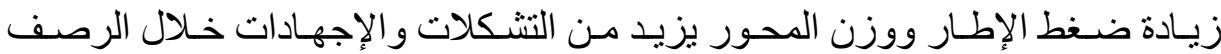

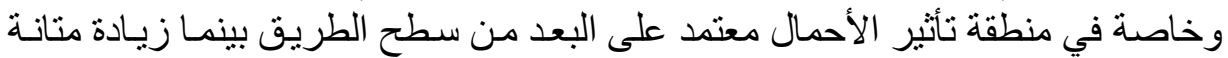
الطبقة السطحية بقلل من هذه الانفعالات الاتئ 8- من المفضل اختيار طبقة سطحية ذات نو عية جيدة و سمك كافي لمقاومـة اجهادات الثـد المحتمل تعرض سطحها أو سطح الطبقة الر ابطة السفلى لهات التها.

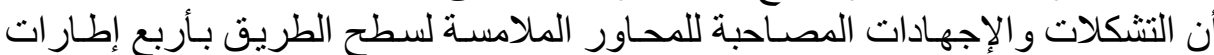
$-9$

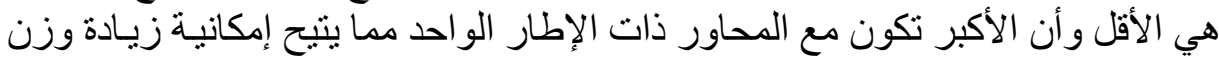

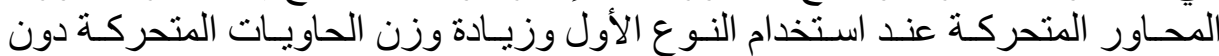
حدوث انهيار بهذه الطرق. 10- مـن المفضـل حمايـة الطريـق و التقليـل مـن التشـكلات و الإجهـادات بـهـ بالعنايـة بإنشـاء وصيانة الطبانات.

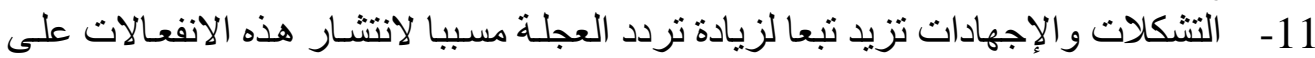

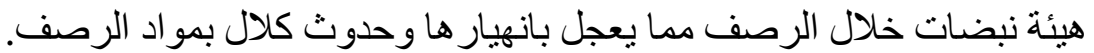

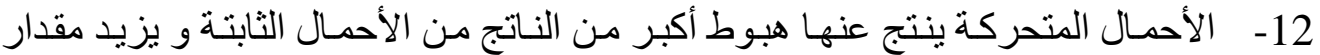
الهبوط تبعا لزيادة السرعة النهة . 13- أن سوء تقدير قيمة الهبوط و والإجهاد بـالطريق المعرض لحمل ثابت يؤدي إلي قصور في تصميم هذه الطرق. 